Research Article

\title{
Suggested New Statistical Parameter for Estimating Joint Roughness Coefficient considering the Shear Direction
}

\author{
Zhiqiang Zhang $\mathbb{D}^{1,2}$ Jiuyang Huan $\mathbb{D}^{1},{ }^{1}$ Ning Li $\mathbb{D},,^{1,2,3}$ and Mingming He $\mathbb{D}^{1}$ \\ ${ }^{1}$ Institute of Geotechnical Engineering, Xi'an University of Technology, Xi'an 710048, China \\ ${ }^{2}$ State Key Laboratory of Eco-Hydraulics in Northwest Arid Region, Xi'an University of Technology, Xi'an 710048, China \\ ${ }^{3}$ Shaanxi Key Laboratory of Loess Mechanics and Engineering, Xi'an University of Technology, Xi'an 710048, China
}

Correspondence should be addressed to Zhiqiang Zhang; 2668709921@qq.com

Received 25 August 2020; Revised 12 January 2021; Accepted 16 February 2021; Published 28 February 2021

Academic Editor: Chunshun Zhang

Copyright (c) 2021 Zhiqiang Zhang et al. This is an open access article distributed under the Creative Commons Attribution License, which permits unrestricted use, distribution, and reproduction in any medium, provided the original work is properly cited.

\begin{abstract}
The 10 standard roughness joint profiles provided a visual comparison to get the joint roughness coefficient (JRC) of rock joint surface, but the accuracy of this method is influenced by human factors. Therefore, many researchers try to evaluate the roughness morphology of joint surface through the statistical parameter method. However, JRC obtained from most of the existing statistical parameters did not reflect the directional property of joint surface. Considering the 10 standard profiles as models of different roughness joints, we proposed a new idea for the accurate estimation of JRC. Based on the concept of area difference, the average of positive area difference $(S a)$ and sum of positive area difference $(S s)$ were first proposed to reflect the roughness of joint surfaces on the basis of directional property, and their fitting relationship with JRC was also investigated. The result showed that the $S a$ and Ss calculated by shearing from right to left (FRTL) and JRC backcalculated from right to left (FRTL) came to a satisfying power law. The correlation between JRC and $S a$ was better than that of $S$ s. The deviation between the predicted value calculated by $S a$ and the true value was smaller than that obtained from the existing statistical parameters. Therefore, $S a$ was recommended as a new statistical parameter to predict the JRC value of joint profile. As the sampling interval increased from 0.5 to $4 \mathrm{~mm}$, the correlation between $S a$ and JRC gradually decreased, and the accuracy of the prediction results also declined. Compared with the single JRC values for joint profiles mentioned in the literature, the forward and reverse JRC were obtained. Based on the laboratory direct shear test of the natural joint surface, the JRC values of two joint surfaces in four shear directions were backcalculated by the JRCJCS model. Based on 3D scanning and point cloud data processing technology, JRC of joint surface in different directions were obtained by $S a$ method, and they are very close to those obtained by JRC-JCS model. It is confirmed that $S a$ could accurately estimate the joint roughness coefficient and reflect its anisotropy.
\end{abstract}

\section{Introduction}

The mechanical behavior of rock mass is much more complex than the complete rock because of its intricate joints and structural planes. The safety and stability of rock mass are mainly controlled by shear deformation along the joints, which is particularly prominent in slope and tunnel engineering [1-4]. For unfilled rock joint, the irregular morphology of the joint surface is one important factor to control the shear strength of joints. Therefore, how to describe it quickly and accurately is of crucial importance [5-8]. Barton [9] proposed the JRC-JCS model widely used in engineering through the direct shear test of 136 natural joint specimens and put forward the joint roughness coefficient (JRC) to quantitatively describe the irregular morphology of the joint for the first time. Through some simple experiments, we can obtain the value of peak shear strength, actual normal stress, basic friction angle, and compressive strength of joint wall (JCS) defined in JRC-JCS model, and then we can get the JRC value through back calculation. However, since we usually hope that the JRC value of joint can be obtained before the direct shear test and used to predict the shear strength of joints, this method was usually used to verify the accuracy of roughness evaluation method. 
In order to predict the joint roughness, Barton and Choubey [10] proposed 10 standard roughness profiles based on the direct shear tests of 136 natural rock specimens. The JRC value of the standard profile is obtained by back calculation from JRC-JCS model with a range of 0 to 20, as shown in Figure 1.

Compared with the surface morphology of natural joints with the standard profiles, the most similar one is selected to obtain the range of joint roughness coefficient. This process is called the empirical comparison method. The International Society for Rock Mechanics [11] recommend these 10 profiles as the standard method for evaluating the joint roughness coefficient, because the empirical comparison method had given the way to determine JRC value for the first time.

The aforementioned empirical comparison method is very convenient and fast. However, the process is greatly affected by experience of engineer, which leads to the floating of the joint roughness coefficient value [13, 14]. Therefore, in order to obtain the roughness coefficient of joints more accurately, statistical parameters such as the straight edge method [15], modified straight edge method [16], fractal dimension $(D)[17,18]$, root mean square roughness index (RMS) and mean square value roughness index (MSV) [19], root mean square of the first deviation of profiles $\left(Z_{2}\right)$ [19-27], structure function (SF) [19-23], standard deviation of the angle $(S D i)$ [21, 22], roughness profile index $\left(R_{P}\right)[21-24,28]$, maximum inclination $\left(\theta_{\max }^{*}\right)$ $[23,24]$, mean positive angle $\left(\theta_{p+}\right)[29]$, modified root mean square $\left(Z^{\prime}{ }_{2}\right)[30]$, and support vector regression (SVR) model [31] had been presented. These aforementioned parameters can be calculated from geometric coordinates of joint profile. In Figure 2 [12], $x_{i}$ and $y_{i}$ are the abscissa and ordinate of joint profile, $\triangle x$ is the distance between the abscissa of adjacent coordinate point and becomes a fixed value at the same sampling interval, and $L$ is the horizontal length of joint profile. The aforementioned statistical parameters have a good correlation with JRC; however, the regression formula between them needs to be applied at a specific sampling interval.

At present, many researchers believed that the rock joint surface has anisotropy, which led to the joint surface sheared in different directions showing different strength and deformation characteristics. In addition, the shear direction of rock joints periodically reversed under cyclic shear conditions. The shear strength values are usually not equal, although the joint morphology does not change much before the last shearing process [32-35]. In the JRC-JCS model proposed by Barton [10], JCS, normal stress, and basic friction angle are all parameters without direction property. Therefore, only the JRC have different values when the shear direction is changed. Thus, it can be concluded that the contribution of the joint surface morphology to the joint roughness in different directions is different and it should be reconsidered on the basis of direction property.

The surface morphology of natural joints is random, and it is impossible to have the same feature in different directions. The default shear direction of the 10 standard profiles proposed by Barton was from left to right (FLTR), which mean that the JRC values in Figure 1 represent the roughness under condition of FLTR. JRC values of the 10 standard profiles under the condition of shearing from right to left (FRTL) are unknown. It is not the same as them obtained under the condition of FLTR.

The aforementioned statistical parameters can predict the JRC value of joint profile, but most of them can reflect the direction property of roughness. The predicted shear strengths of all joints at the shear condition of FLTR and FRTL are the same when using a statistical parameter such as $Z_{2}$ to evaluate JRC and shear strength. Although some scholars [23, 24, 29-31] had proposed directional parameters, the correlation between some of them and JRC is not very good or has not been verified. Obviously, the research on statistical parameters considering shear direction is not rich enough. It is very meaningful to come up with a statistical parameter that can consider the direction property of joint morphology and accurately predict the JRC value.

\section{Preparation for Research}

The data acquisition of joint morphology is the primary task of roughness evaluation. The morphology acquisition and direct shear test of natural joint surface are troublesome, and the JRC obtained are usually used to evaluate the threedimensional roughness of joint surface. In addition, it is difficult to find joint surfaces with different roughness. So, the 10 standard roughness profiles proposed by Barton [9] were usually used as the basis of evaluation method of joint roughness, as shown in Table 1 . The main reason is that their JRC values have been determined, and these values are gradient. Before doing the research, we need to get the discrete data of the joint profiles and validate the reliability of the acquired data to ensure our following research work is accurate.

2.1. Digitization of Ten Standard Roughness Profiles. The original data of the 10 standard roughness profiles were measured by a profile comb (Figure 3 ). The sampling interval of the obtained data was $0.5 \mathrm{~mm}$, while the spacing between the comb teeth was $1 \mathrm{~mm}$. It can be seen that the measured data had a slight error from the actual morphology of joint surface. Digitization process of joint Profile was equivalent to reacquisition of the original data. So, it is not reliable to obtain discrete data of the standard profiles with sampling interval less than $0.5 \mathrm{~mm}$ because this has exceeded the original accuracy of the joint profile. So, the sampling interval of digitization process was set to $0.5 \mathrm{~mm}$ in this section.

We first saved these profiles shown in Figure 1 as images in JPG format by screenshot software and imported these images into GETDATA software. Before the acquisition process, we first need to remove useless pixels from the joint image and set the axes for it. The average horizontal length of 10 standard roughness joint profiles was about $99 \mathrm{~mm}$. According to the processing idea of Zheng and Qi [25] and Huan et al. [35], the horizontal length of the 10 joint profiles 


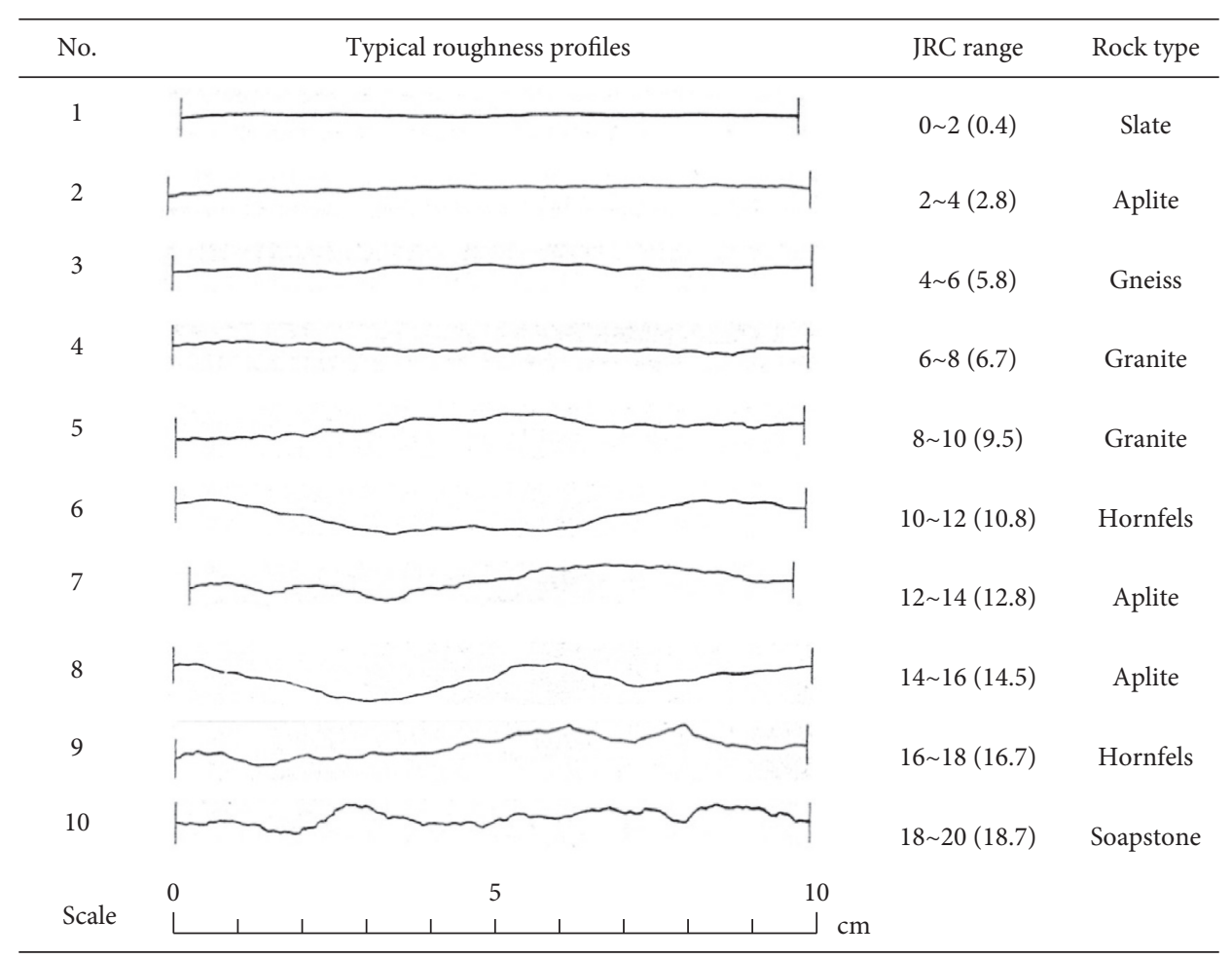

Figure 1: Ten standard roughness joint profiles [10].

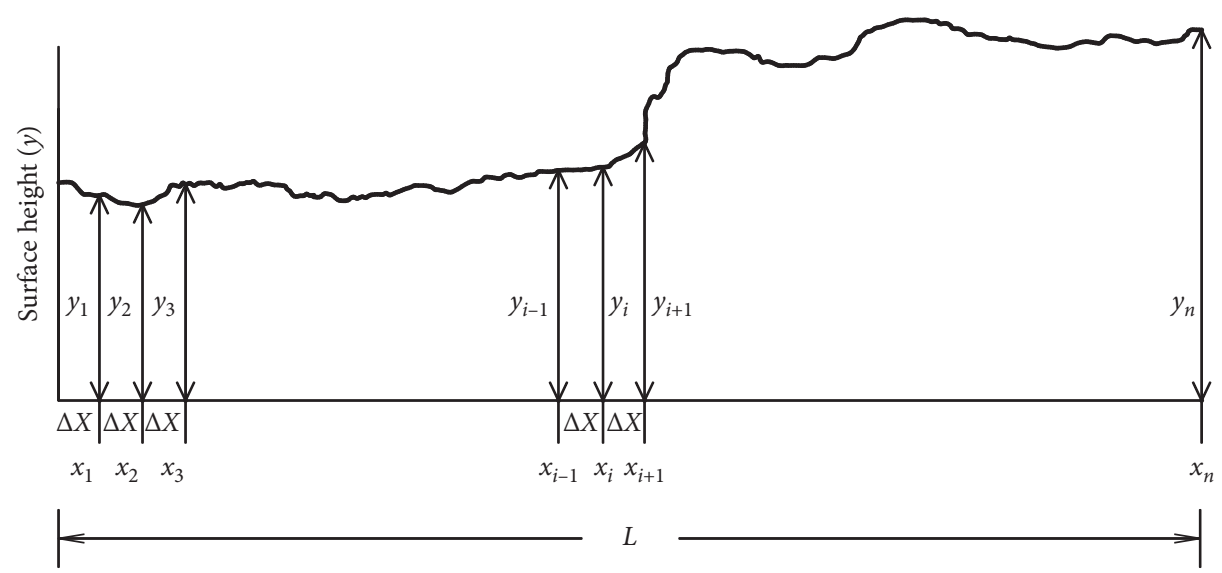

FIgURE 2: The diagram used to define geometric coordinates of a joint profile [12].

TABLE 1: Comparison of relationships of $Z_{2}$ and $R_{P}$ with JRC.

\begin{tabular}{lccc}
\hline Parameter & Equationuation & $R^{2}$ & Reference \\
\hline$Z_{2}$ & $\mathrm{JRC}=51.16\left(Z_{2}\right)^{0.531}-11.44$ & 0.9720 & Jang et al. [23] \\
& $\mathrm{JRC}=62.661\left(Z_{2}\right)^{0.9554}-2$ & 0.9751 & Zheng and Qi [25] \\
& $\mathrm{JRC}=74.47\left(Z_{2}\right)^{0.267}-38.62$ & 0.9761 & This paper \\
\hline \multirow{3}{*}{$R_{P}$} & $\mathrm{JRC}=65.9\left(\mathrm{R}_{\mathrm{P}}-1\right) 0.302-9.65$ & 0.9730 & Jang et al. [23] \\
& $\mathrm{JRC}=104.13\left(\mathrm{R}_{\mathrm{P}}-1\right) 0.5282-1.5$ & 0.9754 & Zheng and Qi [25] \\
& $\mathrm{JRC}=77.06\left(\mathrm{R}_{\mathrm{P}}-1\right) 0.172-29.27$ & 0.9758 & This paper \\
\hline
\end{tabular}




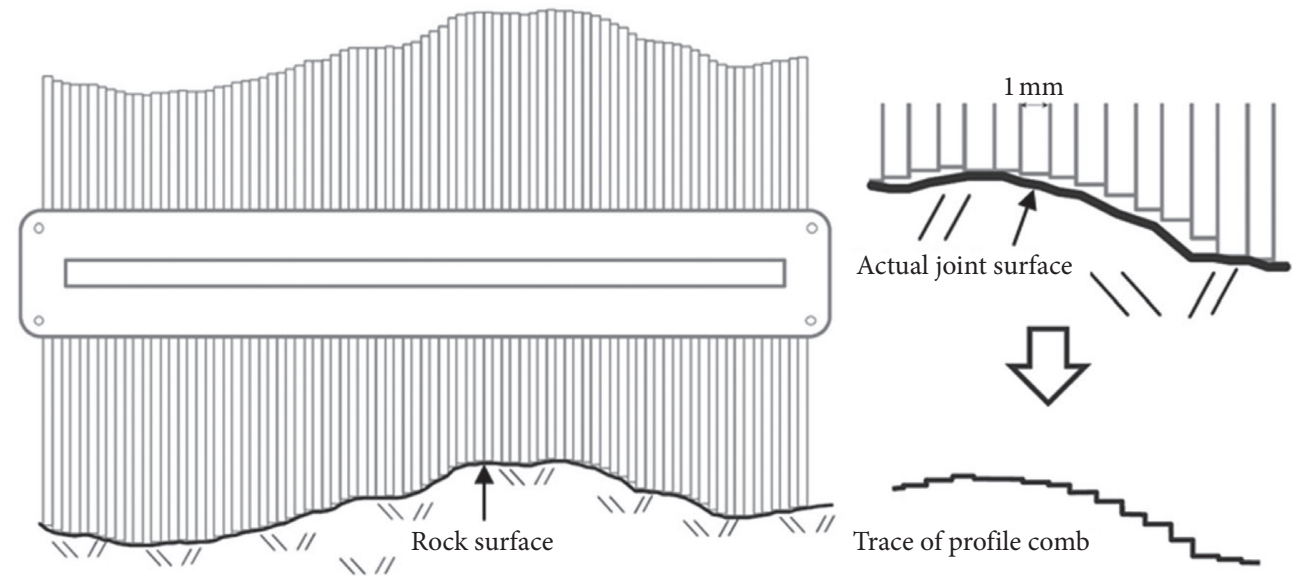

FIgURE 3: Procedure of using a profile comb to get profile of rock joint [23].

was assumed to be $100 \mathrm{~mm}$, and the JRC values of them were assumed to be unchanged.

The geometric coordinates of the profile could be acquired by autocapture mode, and the point capture mode was used to fill the vacant part and modify the singularity point. The data point was at the center of the joint profile by default as shown in Figure 4 . The 10 joint profiles in images were digitized at sampling intervals of $0.5,1.0,2.0$, and $4.0 \mathrm{~mm}$, respectively, for a subsequent study of the effects of sampling intervals. Figure 5 showed the modified 10 standard roughness profiles and the coordinate of starting point was set to $(0,0)$.

2.2. Verification of Profile Data. As mentioned earlier, various statistical parameters had been proposed to describe the morphology of joint surface. In this paper, we first recommended $Z_{2}$ and $R_{P}$ as representatives to verify the accuracy of the obtained joint data. Their definitions are as follows:

$$
\begin{aligned}
Z_{2} & =\left[\frac{1}{L} \int_{x=0}^{x=L}\left(\frac{\mathrm{d} y}{\mathrm{~d} x}\right)^{2} \mathrm{~d} x\right]^{1 / 2} \\
& =\left[\frac{1}{(N-1)(\Delta x)^{2}} \sum_{i=1}^{N-1}\left(y_{i+1}-y_{i}\right)^{2}\right]^{1 / 2}, \\
R_{P} & =\frac{\sum_{i=1}^{N-1}\left[\left(x_{i+1}-x_{i}\right)^{2}+\left(y_{i+1}-y_{i}\right)^{2}\right]^{1 / 2}}{L},
\end{aligned}
$$

where $N$ is the number of discrete points obtained from joint profile and $M$ represents the number of positive slopes. The values of $Z_{2}$, and $R_{P}$ were calculated for the standard roughness profiles at $0.5 \mathrm{~mm}$ sampling interval (Figure 6). Except for the singularity obtained from the fourth profile, the values of $Z_{2}$, and $R_{P}$ tended to increase with the increasing of JRC values. The best fitting curves of statistical parameters and JRC were established using the following:

$$
\mathrm{JRC}=a(P)^{b}+c,
$$

where $P$ represents the statistical parameters and $a, b$, and $c$ represents the regression coefficient. Under the condition of $0.5 \mathrm{~mm}$ sampling interval, the correlation coefficients of $Z_{2}$ and $R_{P}$ with JRC calculated in our paper were larger than those of Jang et al. [23] and Zheng and Qi [25] (Table 1). This has further confirmed that the data of the Barton standard profiles digitized in our paper were highly accurate.

In order to further discuss the rationality of some statistical parameters considering shear direction in evaluating joint roughness, we selected mean positive angle $\left(\theta_{p}^{+}\right)$proposed by Belem et al. [29] and $Z_{2}^{\prime}$ proposed by Zhang et al. [30] to verify their correlation with JRC. Their definitions are as follows:

$$
\begin{aligned}
\theta_{p^{+}} & =\tan ^{-1}\left\{\frac{1}{M_{x^{+}}} \sum_{i=1}^{M_{x^{+}}}\left[\left(\frac{y_{i+1}-y_{i}}{x_{i+1}-x_{i}}\right)_{+}\right]_{i}\right\}, \\
Z_{2}^{\prime} & =\left[\frac{1}{M(\Delta x)^{2}} \sum_{i=1}^{M}\left(\max \left(0, y_{i+1}-y_{i}\right)\right)^{2}\right]^{1 / 2} .
\end{aligned}
$$

Under the condition of $0.5 \mathrm{~mm}$ sampling interval, the relationship curves between the aforementioned two statistical parameters and JRC were shown in Figure 7. It could be seen that the correlation between these two statistical parameters and JRC was not very good, and $R^{2}$ was 0.9313 and 0.9271 , respectively. Therefore, it was necessary to find new statistical parameters to estimate the joint roughness considering the shear direction.

\section{Derivation of New Statistical Parameters}

In order to fill the gaps in the existing studies, two new statistical parameters were proposed in this paper to characterize the roughness of joint profile based on local area. In the definition of DA, the local roughness and shear direction were considered simultaneously.

As shown in Figure 8, the horizontal line located at the lowest point of the profile was defined as the bottom line. The vertical distance between a sampling point on the profile and bottom line was defined as the height. The area surrounded by the adjacent sampling points and bottom line 

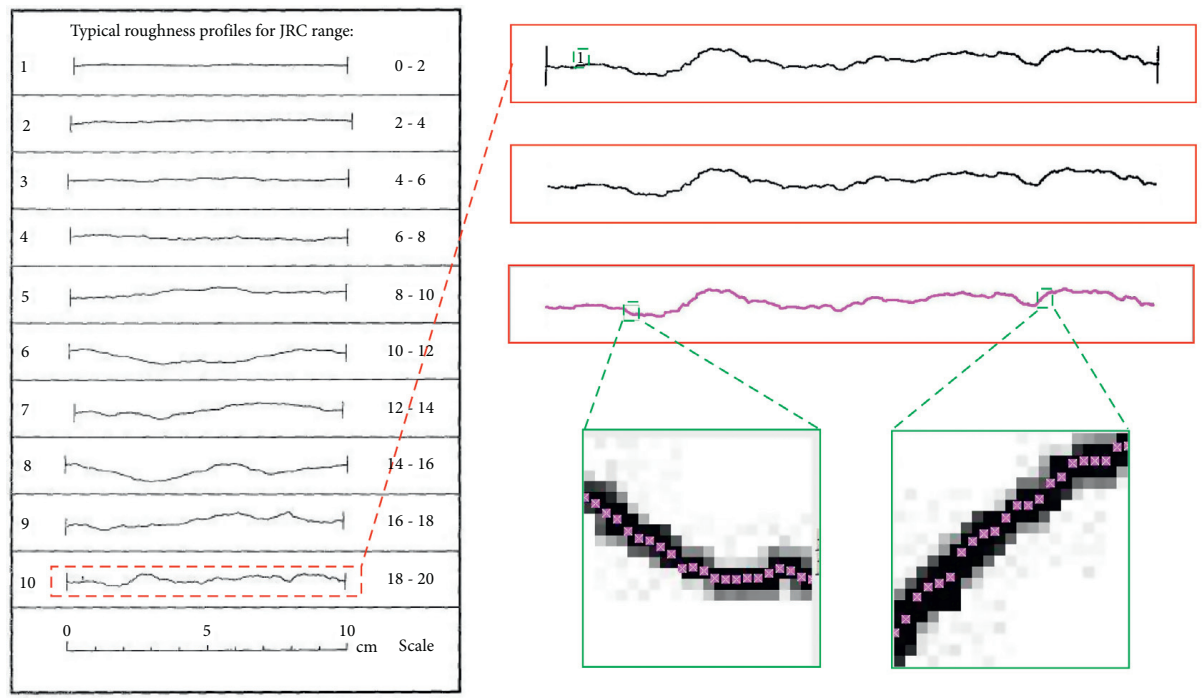
Screenshot of joint profile

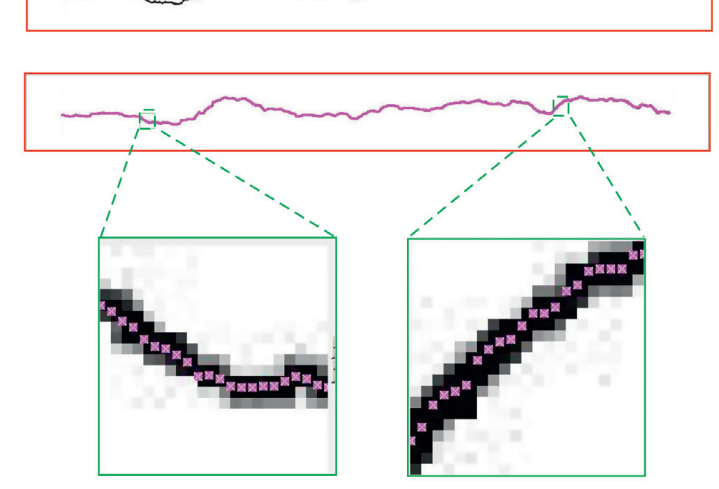

Removal of useless pixels

Data acquisition: the data point is set to the middle of the curve

FIgURE 4: The diagram used to show digitization of a joint profile $(J R C=18-20)$.

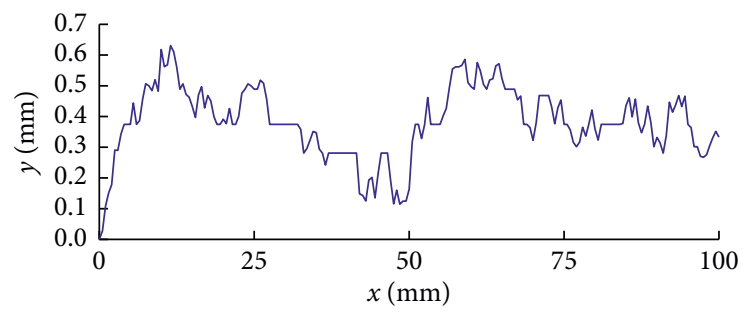

$-\mathrm{JRC}=0.4$

(a)

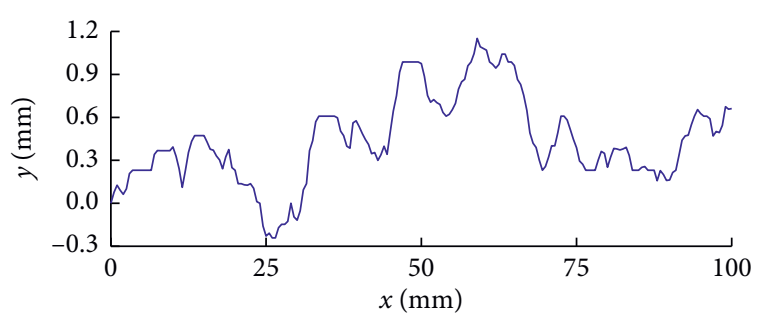

- JRC $=5.8$

(c)

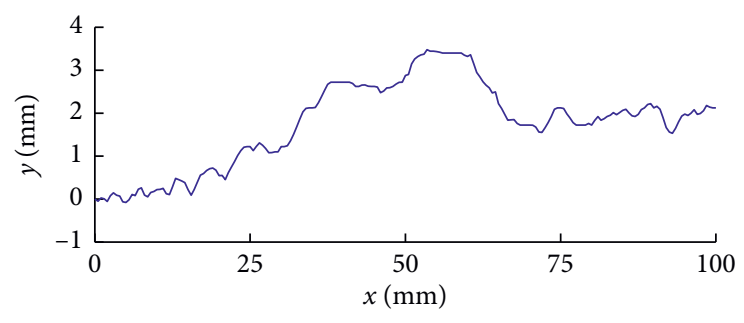

$-\mathrm{JRC}=9.5$

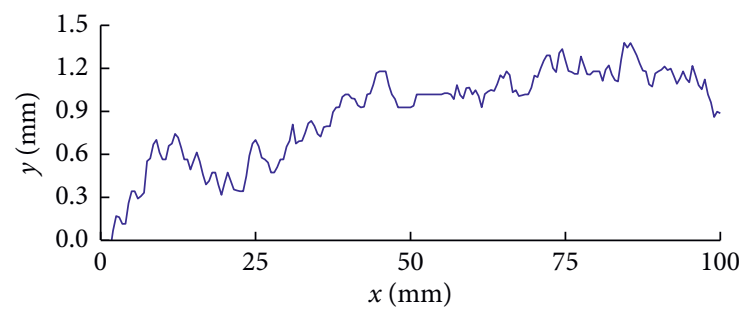

$-\mathrm{JRC}=2.8$

(b)

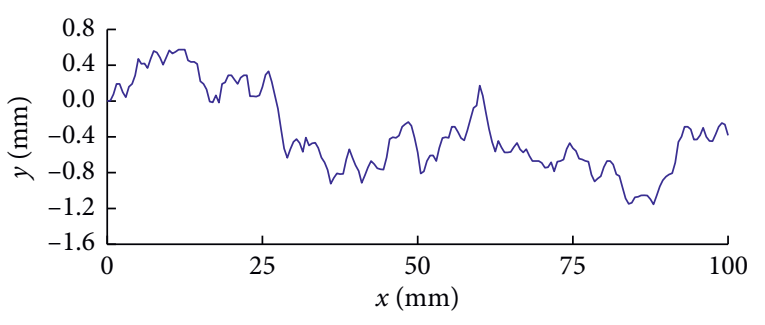

$-\mathrm{JRC}=6.7$

(d)

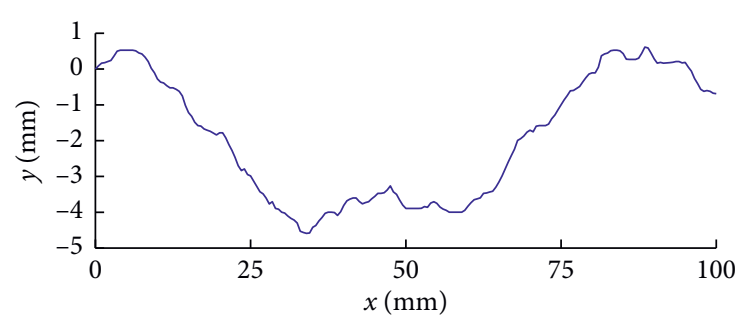

- JRC $=10.8$

(e)

(f)

Figure 5: Continued. 


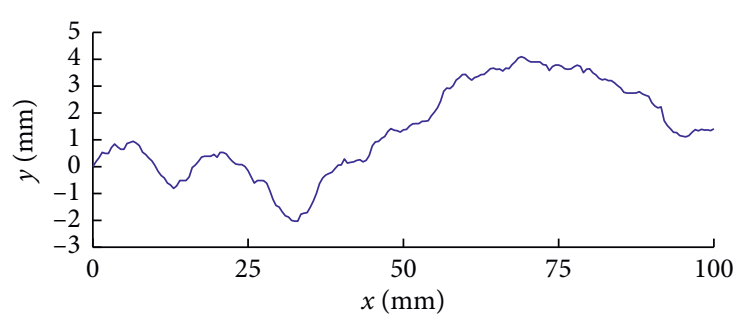

$-\mathrm{JRC}=12.8$

(g)

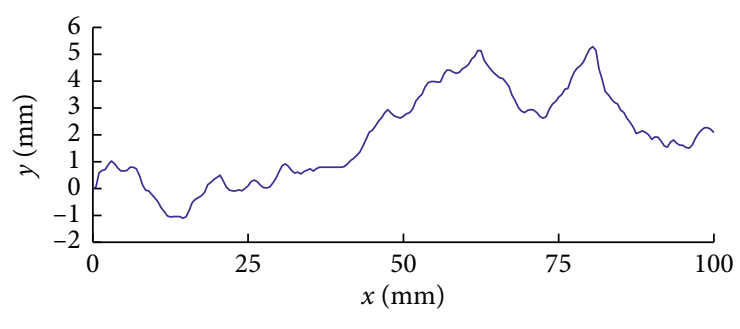

JRC $=16.7$

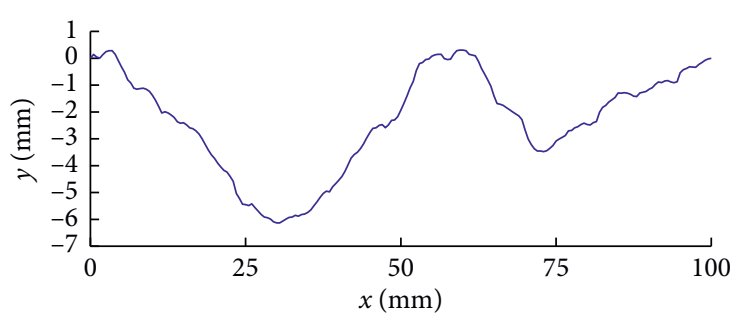

$-\mathrm{JRC}=14.5$

(h)

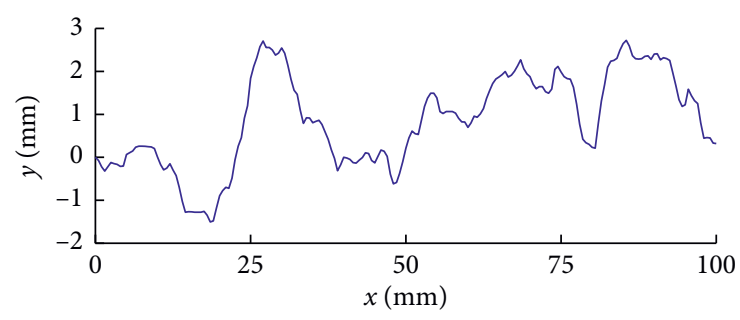

(j)

Figure 5: The modified 10 standard roughness profiles. (a) Profile 1. (b) Profile 2. (c) Profile 3. (d) Profile 4. (e) Profile 5. (f) Profile 6. (g) Profile 7. (h) Profile 8. (i) Profile 9. (j) Profile 10.

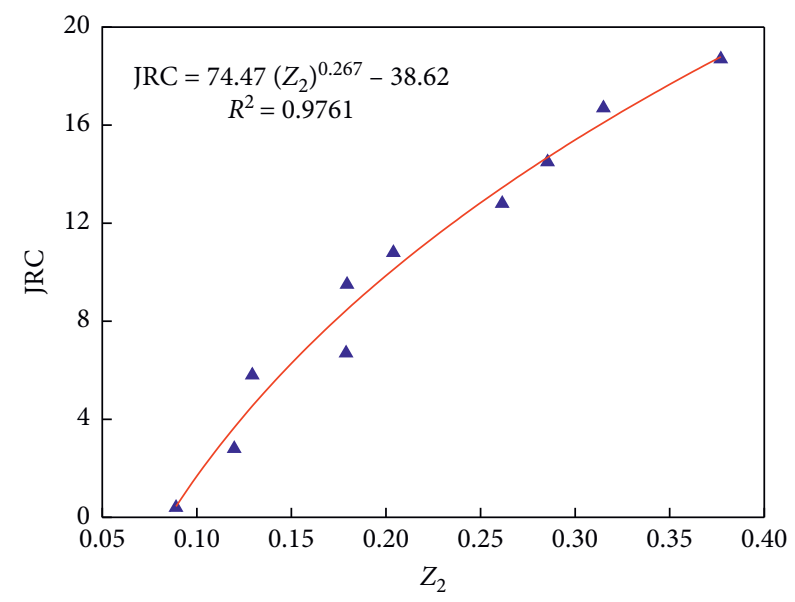

(a)

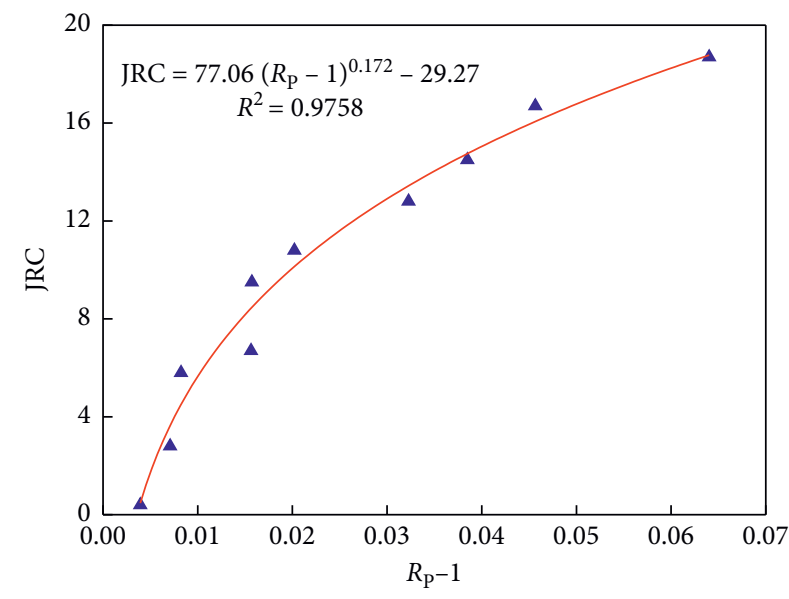

(b)

FIgURe 6: Fitting curves between statistical parameters and JRC. (a) $Z_{2}$. (b) $R_{P}$.

was defined as the local area, and the difference between adjacent areas was defined as DA. They were calculated using the following formula:

$$
\begin{aligned}
h_{i} & =y_{i}-y_{\min }, \\
A_{i} & =\frac{\left(h_{i}+h_{i+1}\right) D x}{2}, \\
\mathrm{DA} & =A_{i+1}-A_{i} .
\end{aligned}
$$

As can be seen from Figure 9, when the joint is smooth, the value of DA is close to zero. When the joint profile is inclined upwards, the value of DA is positive.
When the joint profile is inclined downwards, the value of DA is negative. The distribution of DA calculated from Barton's standard roughness profiles had been obtained, as shown in Figure 10. The abscissa was the numerical range of $\mathrm{DA}$, and the ordinate was the frequency of occurrence. It could be seen that as the joint roughness increased, the numerical range of DA increased obviously. For example, the range of DA obtained from the first profile $(J R C=0-2)$ was from $-0.05 \mathrm{~mm}^{2}$ to $0.06 \mathrm{~mm}^{2}$, the range of DA obtained from the fifth profile (JRC $=8-10$ ) was from $-0.12 \mathrm{~mm}^{2}$ to $0.12 \mathrm{~mm}^{2}$, and the range of DA obtained from the last one $(J R C=18-20)$ was from $-0.25 \mathrm{~mm}^{2}$ to $0.3 \mathrm{~mm}^{2}$. It could be seen that when 


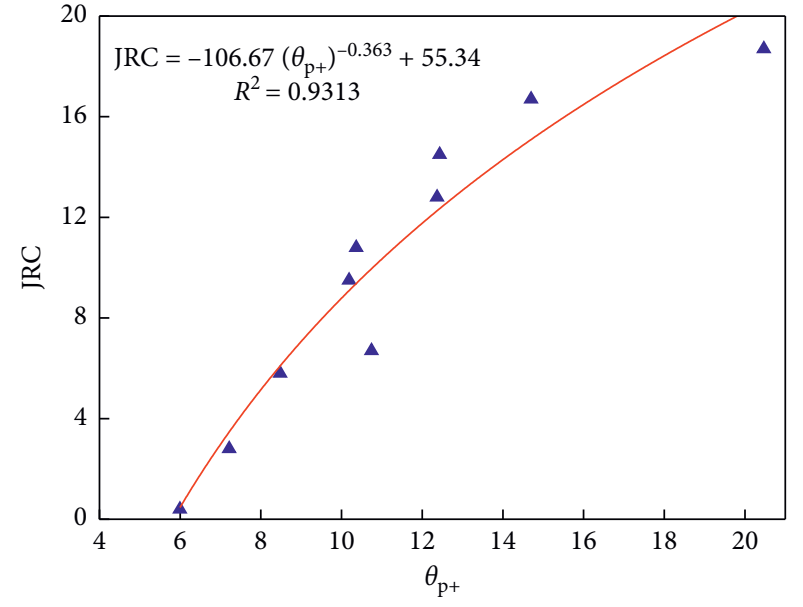

(a)

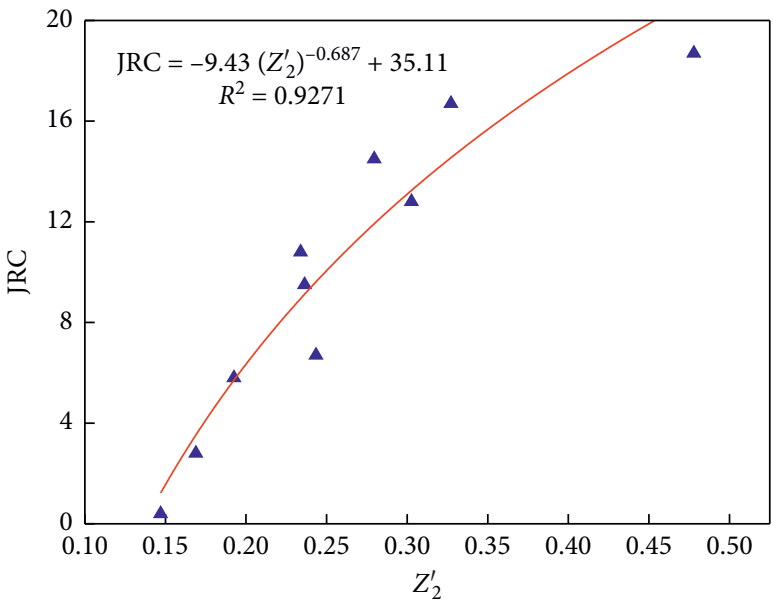

(b)

FIGURE 7: Fitting curves between statistical parameters and JRC. (a) $\theta_{p}^{+}$. (b) $Z_{2}^{\prime}$.

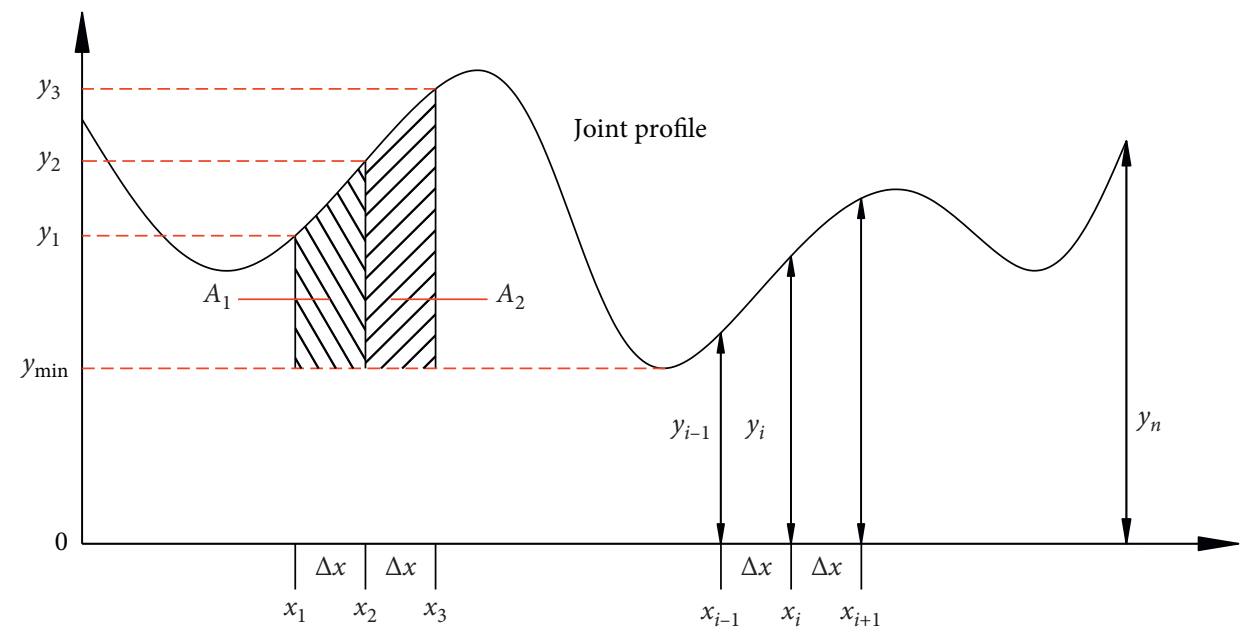

Figure 8: The diagram used to define the local area.

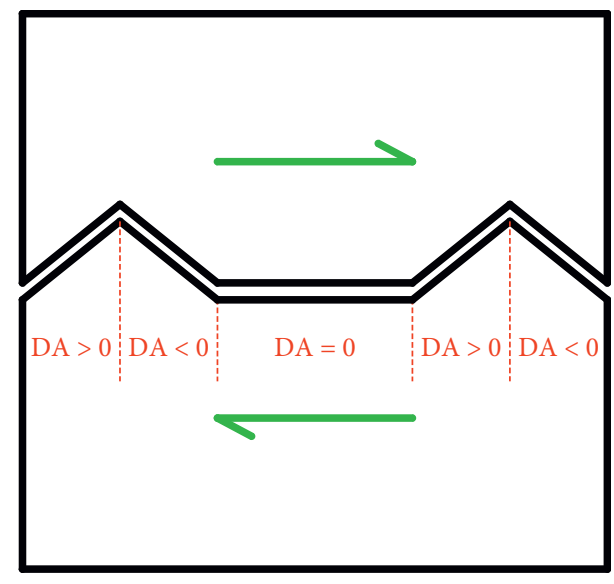

FIgURE 9: The diagram used to explain the positive and negative DA. the roughness of the joint profile changed, the distribution characteristics of DA were very different. In addition, the distribution characteristics of positive DA and negative DA calculated from each profile were also quite different, which could be used to describe the orientation of the morphology.

Under the shear condition of FLTR and FRTL, only the positive DA is counted. The average of positive DA $(\mathrm{Sa})$ and sum of positive DA $(S s)$ are defined to accurately describe the roughness of joint profile considering the directional property, as shown in (5) and (6). There is a certain relationship between $S a$ and $S s$ calculated from the same profile as shown in (7):

$$
\begin{aligned}
& S_{a}=\frac{1}{m} \sum \max (0, \mathrm{DA}), \\
& S_{s}=\sum \max (0, \mathrm{DA}),
\end{aligned}
$$




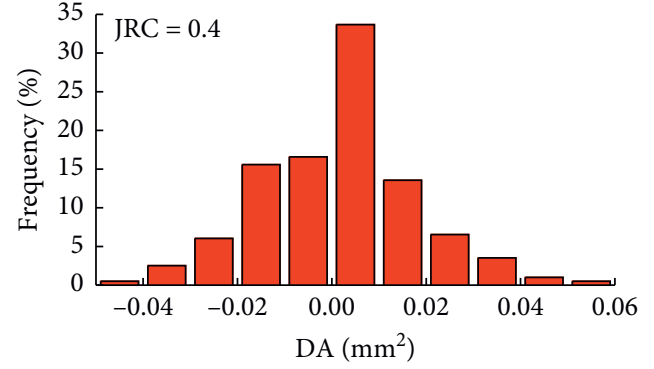

(a)

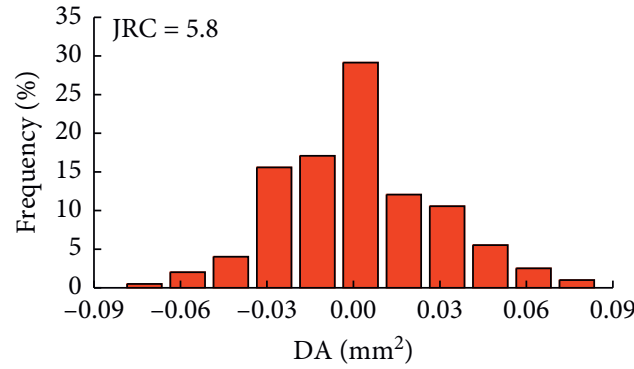

(c)

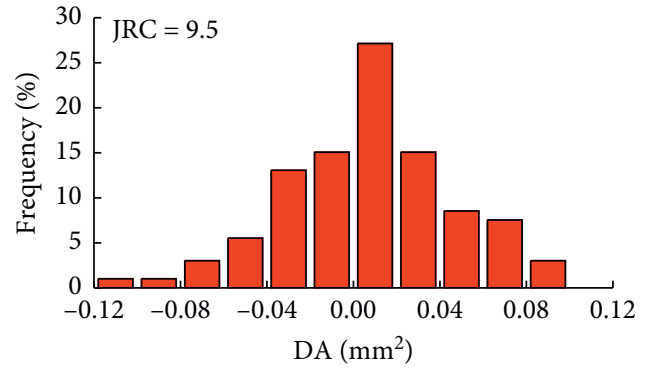

(e)

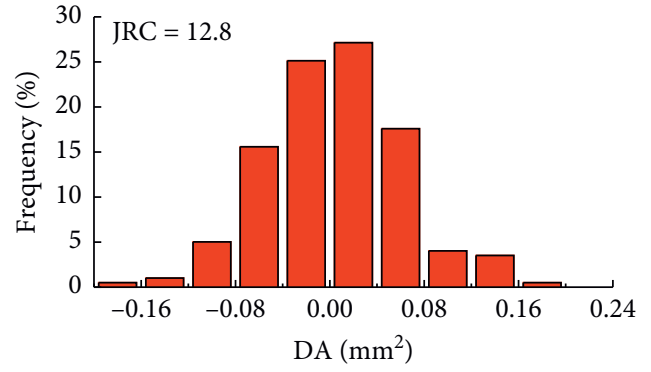

(g)

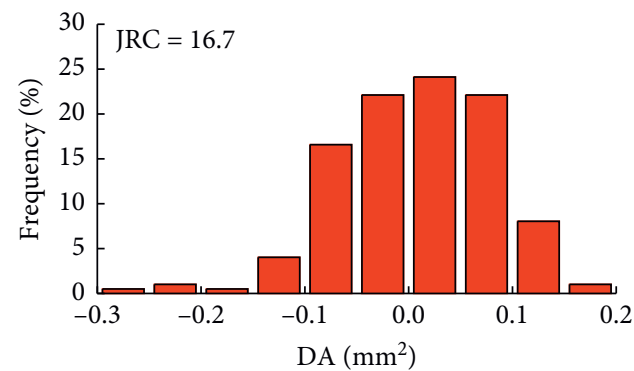

(i)

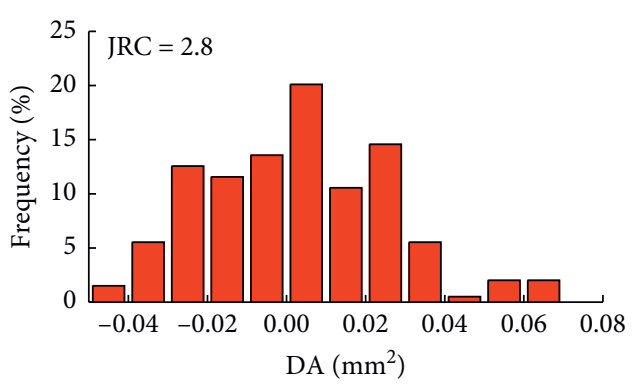

(b)

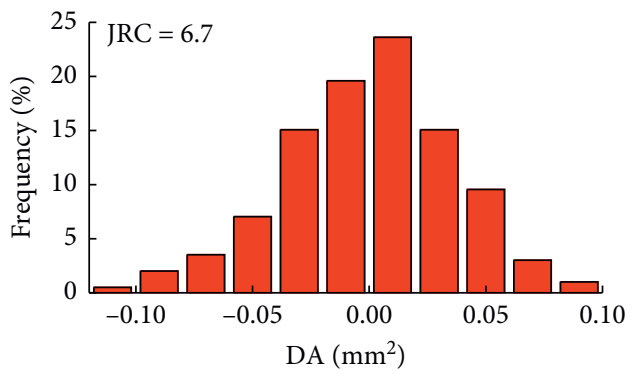

(d)

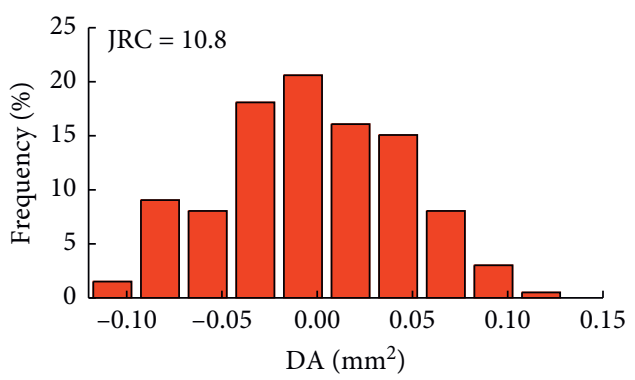

(f)

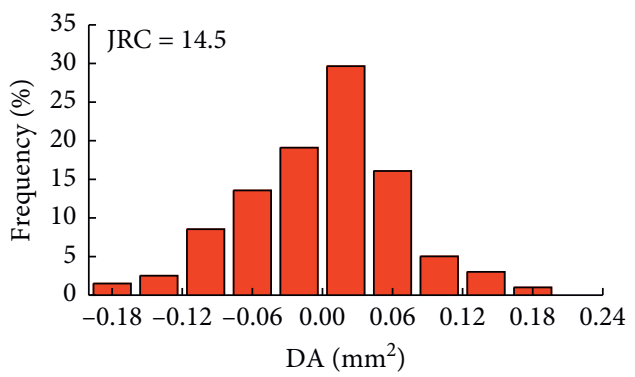

(h)

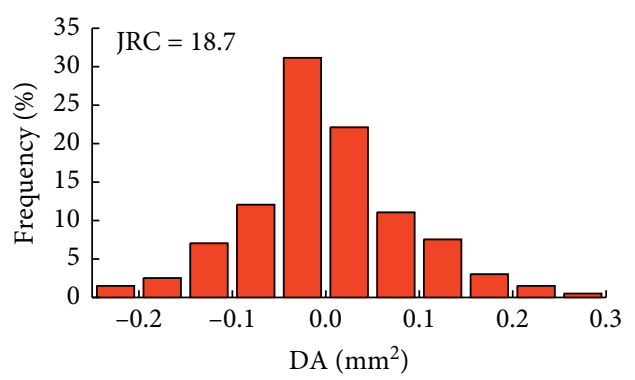

(j)

Figure 10: The distribution of DA calculated from standard roughness profiles. (a) Profile 1. (b) Profile 2. (c) Profile 3. (d) Profile 4. (e) Profile 5. (f) Profile 6. (g) Profile 7. (h) Profile 8. (i) Profile 9. (j) Profile 10. 


$$
S_{a}=\frac{1}{m} S_{s}
$$

where $m$ is the number of positive DA. The values of $m$ calculated from different profiles were different. The values of $S a$ and $S s$ calculated from standard roughness profiles have been obtained under the shear condition of FLTR and FRTL, respectively, as shown in Table 2. The sampling interval for the data of joint profiles is $0.5 \mathrm{~mm}$.

It could be seen that the values of $S a$ and $S s$ obtained under the shear condition of FLTR tend to increase as backcalculated JRC values increase. However, the values of $S a$ and $S s$ calculated from the shear condition of FLTR and backcalculated JRC did not maintain a linear increase. The values of $S a$ calculated from the shear condition of FRTL had singularities in the 4th, 9th, and 10th profiles, and the values of $S s$ calculated from the shear condition of FRTL had singularities in the 4 th and 9 th profile. The fitting function of $S a$ and $S s$ and the backcalculated JRC value were established by the power law function (Equation (3)) as shown in Figure 11.

It could be seen that $S a$ and $S s$ obtained under the shear condition of FLTR had a strong correlation with backcalculated JRC $\left(R^{2}=0.9908, R^{2}=0.9811\right)$. However, the correlation between $S a$ and $S s$ obtained under the shear condition of FRTL with JRC was not good $\left(R^{2}=0.9409\right.$, $\left.R^{2}=0.9420\right)$.

$$
\mathrm{JRC}=115.22\left(S_{a}\right)^{0.221}-45.47 .
$$

The correlation between the statistical parameters $S a$ and $S s$ under the shear condition of FRTL with backcalculated JRC had a better correlation. They had the same directional property as the backcalculated JRC. Sa was better correlated with JRC than $S$ s; therefore $S a$ was considered to be able to describe the joint profile roughness well, considering the directional property. Equation (8) was recommended for estimating the joint JRC at $0.5 \mathrm{~mm}$ sampling interval. The JRC value can only describe the joint roughness corresponding to the shear direction considered in the calculation of statistical parameters.

In order to verify the accuracy of the statistical parameters in estimating the JRC, the deviation value between $J R C_{\text {pre }}$ and $J R C_{\text {true }}$ was proposed as shown in (9). JRC pre was the predicted JRC value obtained from the regression formula, and JRC true represented the actual JRC value of the joint profile. The results of deviation calculated from $Z_{2}, R_{p}$, and $S a$ are shown in Table 3:

$$
\text { deviation }=\mathrm{JRC}_{\text {pre }}-\mathrm{JRC}_{\text {true }} \text {. }
$$

It could be seen that the maximum deviation of $Z_{2}$ and $R_{P}$ in evaluating the joint JRC was 1.738 and 1.737 . The deviations of these two statistical parameters in evaluating the JRC value of the 3 th, 4 th, and 5 th profile were both greater than one. In contrast, the maximum deviation of $\mathrm{Sa}$ was 0.865 , and no deviation was greater than 1 . However, the $J R C_{\text {pre }}$ value obtained from the first profile was less than zero, which indicated that the $S a$ cannot well evaluate the roughness of smooth joints. The JRC value of joint profile was supposed to be greater than 0 , so the $S a$ calculated at $0.5 \mathrm{~mm}$ sampling interval should be greater than $0.01489 \mathrm{~mm}^{2}$. The mean deviation was proposed to describe the accuracy of the statistical parameters in evaluating the JRC of joint profile. It could be seen that the mean deviation obtained by $S a$ was smaller than $Z_{2}$ and $R_{P}$, which further showed that $S a$ could well estimate the roughness of joint profile.

In order to better understand the directional properties of joint roughness, the forward JRC was defined to describe the roughness obtained under the shear condition of FLTR, and the reverse JRC was defined to describe the roughness obtained under the shear condition of FRTL. Under the shear condition of FRTL, the values of $S a$ corresponding to standard roughness profiles were calculated by (8). The reverse JRC of each profile could be obtained by substituting the data of $S a$ into (8) as shown in Table 4. It could be seen that the values of the forward JRC and reverse JRC of each profile were very different. The forward JRC values were greater than the reverse JRC except for the 4th, 6th, and 8th profile. The reverse JRC value of the first profile was negative, which further illustrated that $\mathrm{Sa}$ could not predict the roughness of smooth joint. The numerical difference between forward JRC and reverse JRC values calculated from the $S a$ well verified the directional property of joint roughness, which could not be achieved by statistical parameters, such as $Z_{2}$ and $R_{P}$. Under the shear condition of FRTL, the ordinal numbers of the standard roughness profiles had changed according to the value of the reverse JRC. Table 4 showed the reordering of standard roughness profiles, which had been adjusted in the 4 th, 5 th, 8 th, and 10th profile.

\section{Effect of Sampling Interval}

As mentioned earlier, the values of existing statistical parameters and their correlation with the roughness are affected by the sampling interval of the joint profile. High precision data can better describe the true morphological features of the joint profile, but it is not easy to obtain. In this paper, Barton's 10 standard roughness profiles were digitized at $0.5,1,2$, and $4 \mathrm{~mm}$ sampling interval, respectively. The $S a$ was calculated under the shear condition of FLTR and regressed with value of the forward JRC. The results were shown in Table 5 and Figure 12.

As can be seen from Table 5, the value of $S a$ increased significantly with the increase of sampling interval, which indicated that $\mathrm{Sa}$ has a great sensitivity to the sampling interval. A small error in the calculation will result in a large deviation in the value of $S a$, which will lead to a deviation of the $\mathrm{JRC}_{\text {pre }}$ value. It is necessary to ensure that the $S a$ value and corresponding regression formula are under the same sampling interval condition in order to obtain an accurate $\mathrm{JRC}_{\text {pre }}$ value.

As can be seen from Figure 12, as the sampling interval gradually increased from 0.5 to $4 \mathrm{~mm}$, the correlation between $S a$ and forward JRC decreases. When the sampling interval is 0.5 and $1 \mathrm{~mm}$, the value of $S a$ increased with the increase of the joint number. However, when the sampling 
TABLE 2: Values of $S a$ and $S s$ calculated under the shear condition of FLTR and FRTL.

\begin{tabular}{|c|c|c|c|c|c|c|c|}
\hline Profile no. & JRC value & $\begin{array}{c}\text { FLTR } \\
\mathrm{m}\end{array}$ & $S a\left(\mathrm{~mm}^{2}\right)$ & Ss $\left(\mathrm{mm}^{2}\right)$ & $\begin{array}{c}\text { FRTL } \\
\mathrm{m}\end{array}$ & $\mathrm{Sa}\left(\mathrm{mm}^{2}\right)$ & Ss $\left(\mathrm{mm}^{2}\right)$ \\
\hline 1 & 0.4 & 86 & 0.01452 & 1.24906 & 82 & 0.01323 & 1.08487 \\
\hline 2 & 2.8 & 98 & 0.02094 & 2.05260 & 89 & 0.01773 & 1.57769 \\
\hline 3 & 5.8 & 82 & 0.02682 & 2.19928 & 95 & 0.01988 & 1.88889 \\
\hline 4 & 6.7 & 102 & 0.02752 & 2.80657 & 95 & 0.03125 & 2.96906 \\
\hline 5 & 9.5 & 106 & 0.03278 & 3.47417 & 77 & 0.03118 & 2.40111 \\
\hline 6 & 10.8 & 93 & 0.03785 & 3.52032 & 95 & 0.04088 & 3.88361 \\
\hline 7 & 12.8 & 100 & 0.04738 & 4.73797 & 94 & 0.04358 & 4.09690 \\
\hline 8 & 14.5 & 109 & 0.04895 & 5.33536 & 90 & 0.05975 & 5.37718 \\
\hline 9 & 16.7 & 103 & 0.06063 & 6.24455 & 89 & 0.05827 & 5.18623 \\
\hline 10 & 18.7 & 90 & 0.07181 & 6.46292 & 108 & 0.05816 & 6.28157 \\
\hline
\end{tabular}

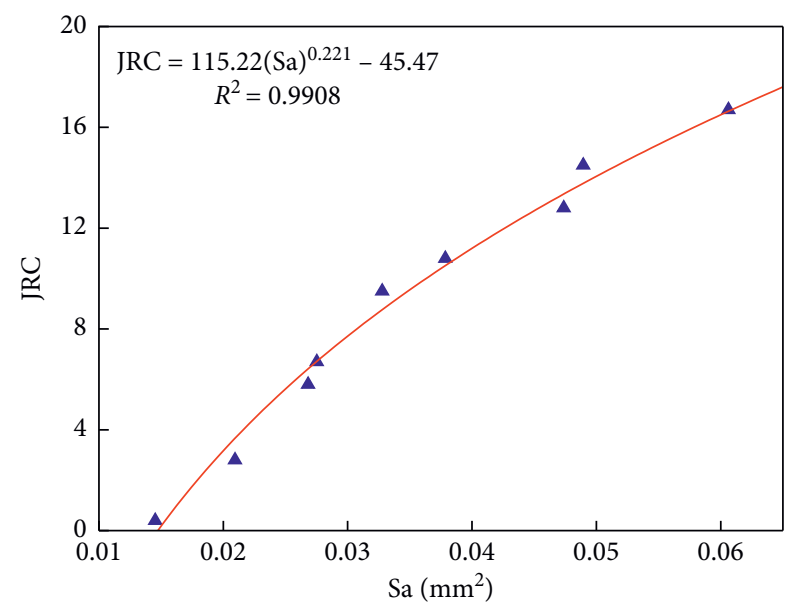

(a)

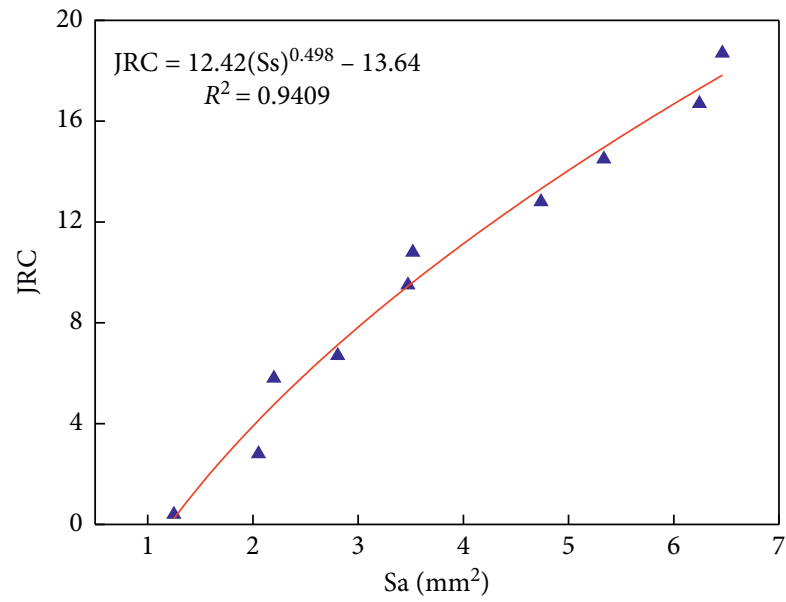

(c)

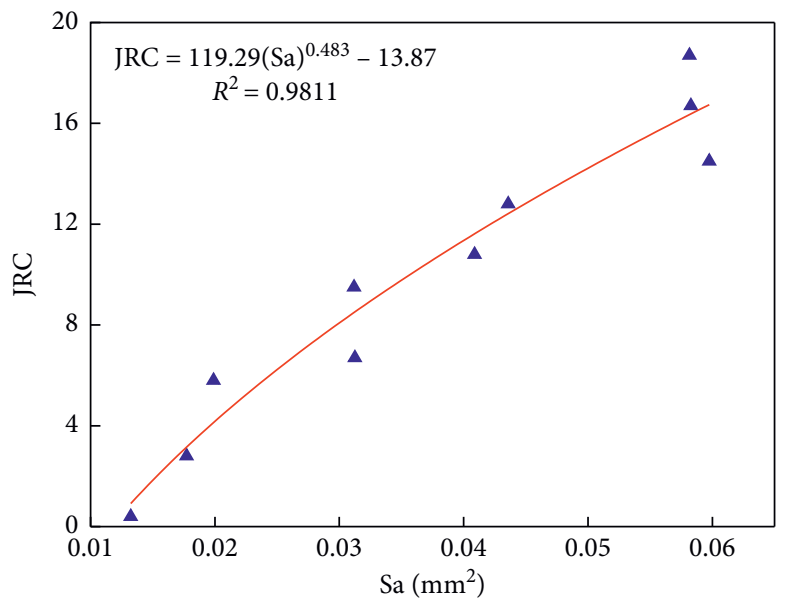

(b)

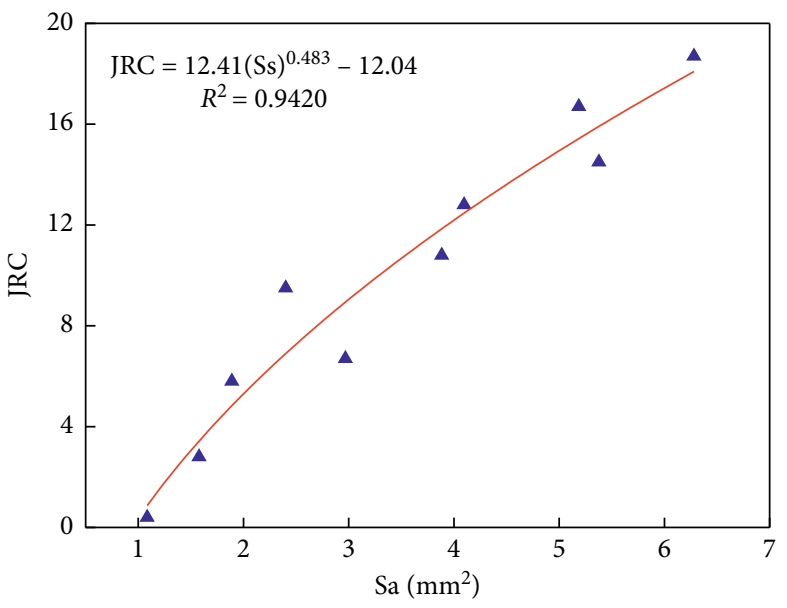

(d)

Figure 11: Fitting curves between statistical parameters and JRC. (a) Sa, FLTR. (b) Sa, FRTL. (c) Ss, FLTR. (d) Ss, FRTL.

interval was $2 \mathrm{~mm}$, the $S a$ calculated from the 3rd and 9th profiles was less than the value calculated from the preceding profile. When the sampling interval was $4 \mathrm{~mm}$, the $S a$ values calculated from the 9th and 10th profiles were less than the value calculated from the preceding profile.

The deviation between $\mathrm{JRC}_{\text {pre }}$ and $\mathrm{JRC}_{\text {true }}$ was obtained for each sampling interval using (9), as shown in Table 6. The deviation was always less than one at the $0.5 \mathrm{~mm}$ sampling interval. When the sampling interval was $1 \mathrm{~mm}$, the deviation of the 3rd profile was greater than one. When the sampling interval was $2 \mathrm{~mm}$, deviation greater than one occurred five times and the deviation of the 9th profile was greater than two. When the sampling interval was $4 \mathrm{~mm}$, deviation greater than one occurred six times. What is more, 
TABLE 3: Comparison of deviation between $\mathrm{JRC}_{\text {pre }}$ and $\mathrm{JRC}_{\text {true }}$ calculated from $Z_{2}, R_{p}$, and $S a$.

\begin{tabular}{|c|c|c|c|c|c|c|}
\hline \multirow{3}{*}{$\mathrm{JRC}_{\text {true }}$} & \multicolumn{6}{|c|}{ Statistical parameters } \\
\hline & \multicolumn{2}{|c|}{$Z_{2}$} & \multicolumn{2}{|c|}{$R_{P}$} & \multicolumn{2}{|c|}{$\mathrm{Sa}\left(\mathrm{mm}^{2}\right)$} \\
\hline & $\mathrm{JRC}_{\text {pre }}$ & Deviation & $\mathrm{JRC}_{\text {pre }}$ & Deviation & $\mathrm{JRC}_{\text {pre }}$ & Deviation \\
\hline 0.4 & 0.444 & 0.044 & 0.472 & 0.072 & -0.145 & 0.545 \\
\hline 2.8 & 3.665 & 0.865 & 3.645 & 0.845 & 3.665 & -0.865 \\
\hline 5.8 & 4.539 & -1.261 & 4.506 & -1.294 & 6.418 & -0.618 \\
\hline 6.7 & 8.438 & 1.738 & 8.437 & 1.737 & 6.712 & -0.012 \\
\hline 9.5 & 8.477 & -1.023 & 8.474 & -1.026 & 8.763 & 0.737 \\
\hline 10.8 & 10.111 & -0.689 & 10.140 & -0.660 & 10.513 & 0.287 \\
\hline 12.8 & 13.450 & 0.650 & 13.438 & 0.638 & 13.354 & -0.554 \\
\hline 14.5 & 14.683 & 0.183 & 14.750 & 0.250 & 13.778 & 0.722 \\
\hline 16.7 & 16.104 & -0.596 & 16.063 & -0.637 & 16.640 & 0.060 \\
\hline 18.7 & 18.789 & 0.089 & 18.776 & 0.076 & 19.002 & -0.302 \\
\hline Mean & & 0.714 & & 0.724 & & 0.470 \\
\hline
\end{tabular}

TABLE 4: Reordering of standard roughness profiles according to the reverse JRC.

\begin{tabular}{lccc}
\hline Profile no. & The forward JRC & Profile no. & The reverse JRC \\
\hline 1 & 0.4 & 1 & -1.171 \\
2 & 2.8 & 2 & 1.788 \\
3 & 5.8 & 3 & 3.002 \\
4 & 6.7 & $4(5)$ & 8.097 \\
5 & 9.5 & $5(4)$ & 8.071 \\
6 & 10.8 & 6 & 11.372 \\
7 & 12.8 & 7 & 12.183 \\
8 & 14.5 & $8(10)$ & 16.345 \\
9 & 16.7 & 9 & 16.004 \\
10 & 18.7 & $10(8)$ & 15.979 \\
\hline
\end{tabular}

TABLE 5: The fitting relationship between $S a$ and JRC under different sampling intervals.

\begin{tabular}{lcccc}
\hline \multirow{2}{*}{ The forward JRC } & \multicolumn{4}{c}{ Sampling interval (mm) } \\
& 0.5 & 1 & 2 & 4 \\
\hline 0.4 & 0.01452 & 0.04118 & 0.11345 & 0.31552 \\
2.8 & 0.02094 & 0.05565 & 0.14560 & 0.45618 \\
5.8 & 0.02682 & 0.07141 & 0.25664 & 0.64537 \\
6.7 & 0.02752 & 0.09130 & 0.23924 & 0.83009 \\
9.5 & 0.03278 & 0.11058 & 0.31122 & 0.93673 \\
10.8 & 0.03785 & 0.14209 & 0.51260 & 1.73843 \\
12.8 & 0.04738 & 0.16917 & 0.57792 & 2.06891 \\
14.5 & 0.04895 & 0.18958 & 0.66111 & 2.81650 \\
16.7 & 0.06063 & 0.20083 & 0.60804 & 1.93270 \\
18.7 & 0.07181 & 0.23141 & 0.80806 & 2.25260 \\
\hline
\end{tabular}

deviation greater than two occurred four times, and the deviation of the 10th profile was greater than three. As the sampling interval increases from $0.5 \mathrm{~mm}$ to $4 \mathrm{~mm}$, the calculated mean deviation increased from 0.47 to 1.505 , which indicated that as the sampling interval increased, the accuracy of $\mathrm{JRC}_{\text {pre }}$ calculated by the regression formula decreased.

As the sampling interval increased, the number of points obtained from the joint profile decreased significantly. For example, the number of discrete points was 201 at a spacing interval of $0.5 \mathrm{~mm}$, while the number of discrete points was only 26 at a spacing interval of $4 \mathrm{~mm}$. It could be considered that the profile data obtained under the condition of large sampling interval ignored many morphologies, and the calculated statistical parameters could not describe the roughness of joint profile very well. Therefore, we recommended using the regression formula with a sampling interval of $0.5 \mathrm{~mm}$ to accurately predict the JRC of joint profile.

\section{Verification of Using $S a$ to Evaluate JRC}

In order to verify the advantage of $S a$ in evaluating the roughness of joint profile, the roughness of the joint profile given in the literatures [20,30,36-39] and the natural joint surface were separately evaluated.

5.1. JRC Estimation of the Joint Profiles Given in the Literature Studies. We first performed the corresponding digitization process on the joint profile given by literatures [20, 30, 36-39] at $0.5 \mathrm{~mm}$ sampling interval. In many cases, natural joints are longer than the 10 standard profiles. Considering the influence of size effect on JRC value, Barton [40] proposed the following:

$$
\mathrm{JRC}_{n}=\mathrm{JRC}_{0}\left(\frac{L_{n}}{L_{0}}\right)^{-0.02 \mathrm{JRC}_{0}},
$$




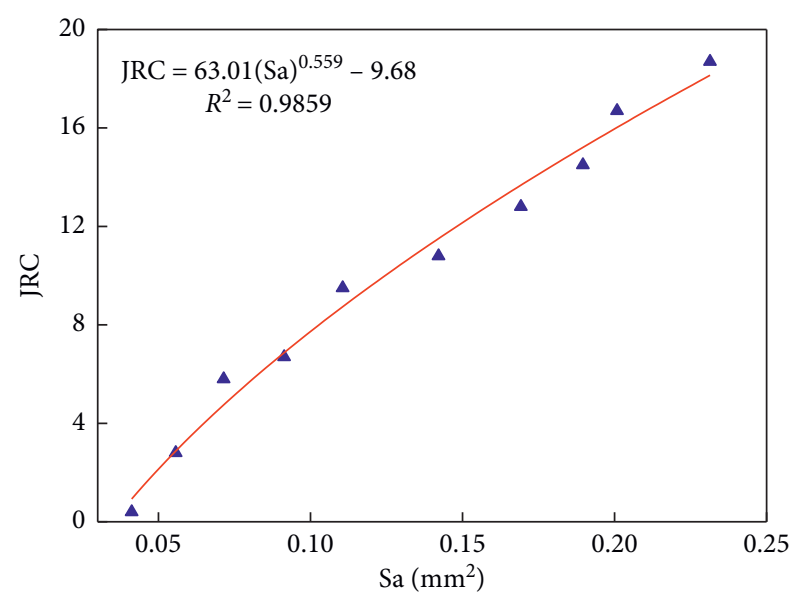

(a)

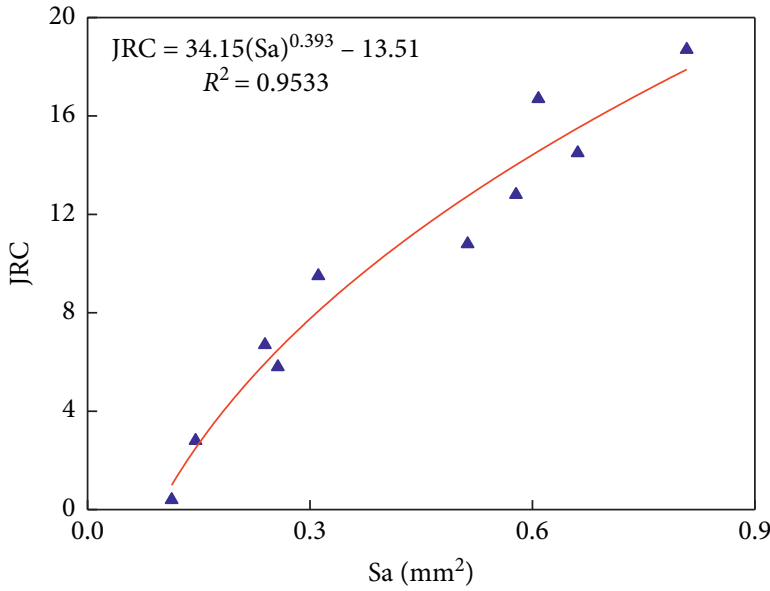

(b)

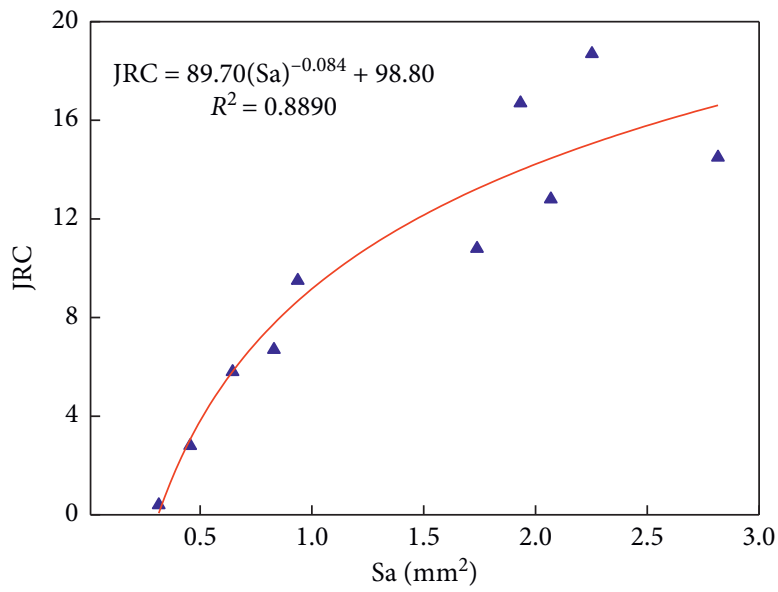

(c)

FiguRE 12: Fitting curves between statistical parameters and JRC. (a) $1.0 \mathrm{~mm}$ sampling interval. (b) $2.0 \mathrm{~mm}$ sampling interval. (c) $4.0 \mathrm{~mm}$ sampling interval.

where $\mathrm{JRC}_{n}$ is the joint roughness coefficient value of joint for study, $L_{n}$ is the length of natural joints, and $L_{O}$ represents the laboratory scale and the length of joint is close to $100 \mathrm{~mm}$. The $S a$ and corresponding JRC values calculated under the shear condition of FLTR and FRTL are shown in Table 7 . The JRC values of joint $1,3,6,7,8$, $18,19,20$, and 21 were corrected by (10). The results showed that the difference between the forward and reverse JRC of the joint profile was sometimes small but at other times large. In addition, it can be seen that the joint JRC can exceed the upper limit of 20 set by Barton, which is consistent with research findings of Du et al. [16]. This showed that the JRC calculated by the statistical parameter $S a$ not only can well reflect the rough morphology but also can distinguish the differences of roughness in different shear directions.

5.2. JRCEstimation of the Natural Joint Surface. The two joint specimens (numbers $\mathrm{J}-1$ and $\mathrm{J}-2$ ) used to estimate the roughness were collected from Taibai Mountain, Xi'an City, Shaanxi Province, China. The rock type is granite, and the plane size is about $100 \mathrm{~mm} \times 100 \mathrm{~mm}$. The joint surfaces were produced by artificial load damage at the quarry. The 3D point cloud data of joint surfaces were obtained by the 3D Scanner Go! SCAN 20, and then they were imported into Geomagic Studio software.

The joint surface data was separated through data processing, and the joint surface mold was made by $3 \mathrm{D}$ printing technology. The rough joint samples used in direct shear test were poured with cement mortar, and the smooth joint samples and uniaxial specimens were made additionally. The mass ratio of water, cement, and standard sand is $1: 2: 3$. Then, the direct shear tests were carried out in four shear directions, and the normal stress was $2,4,6$, and $4 \mathrm{MPa}$ separately. Figure 13 showed the production process of joint samples with J-1 joint as an example.

In this section, the roughness of joint surface in four different directions was represented by averaging the roughness of the joint profile. In each shear direction, 201 joint profiles were extracted with an interval of $0.5 \mathrm{~mm}$ by Geomagic Studio software. The JRC of each joint profile was obtained by calculating its $S a$ value at $0.5 \mathrm{~mm}$ sampling interval and substituting it into (8). 
TABLE 6: Comparison of deviation between $\mathrm{JRC}_{\text {pre }}$ and $\mathrm{JRC}_{\text {true }}$ calculated from $\mathrm{Sa}$ under different sampling intervals.

\begin{tabular}{|c|c|c|c|c|c|c|c|c|}
\hline \multirow{3}{*}{$\mathrm{JRC}_{\text {true }}$} & \multicolumn{8}{|c|}{ Sampling interval $(\mathrm{mm})$} \\
\hline & \multicolumn{2}{|c|}{0.5} & \multicolumn{2}{|c|}{1} & \multicolumn{2}{|c|}{2} & \multicolumn{2}{|c|}{4} \\
\hline & $J_{R C}$ pre & Deviation & $J_{R C}$ pre & Deviation & $\mathrm{JRC}_{\text {pre }}$ & Deviation & $\mathrm{JRC}_{\text {pre }}$ & Deviation \\
\hline 0.4 & -0.145 & 0.545 & 0.928 & -0.528 & 0.995 & -0.595 & 0.068 & 0.332 \\
\hline 2.8 & 3.665 & -0.865 & 2.871 & -0.071 & 2.491 & 0.309 & 3.071 & -0.271 \\
\hline 5.8 & 6.418 & -0.618 & 4.746 & 1.054 & 6.488 & -0.688 & 5.813 & -0.013 \\
\hline 6.7 & 6.712 & -0.012 & 6.868 & -0.168 & 5.943 & 0.757 & 7.753 & -1.053 \\
\hline 9.5 & 8.763 & 0.737 & 8.737 & 0.763 & 8.064 & 1.436 & 8.670 & 0.830 \\
\hline 10.8 & 10.513 & 0.287 & 11.506 & -0.706 & 12.743 & -1.943 & 13.220 & -2.420 \\
\hline 12.8 & 13.354 & -0.554 & 13.674 & -0.874 & 14.011 & -1.211 & 14.459 & -1.659 \\
\hline 14.5 & 13.778 & 0.722 & 15.208 & -0.708 & 15.507 & -1.007 & 16.611 & -2.111 \\
\hline 16.7 & 16.640 & 0.060 & 16.022 & 0.678 & 14.567 & 2.133 & 13.977 & 2.723 \\
\hline 18.7 & 19.002 & -0.302 & 18.140 & 0.560 & 17.891 & 0.809 & 15.058 & 3.642 \\
\hline Mean & & 0.470 & & 0.661 & & 1.089 & & 1.505 \\
\hline
\end{tabular}

TABLE 7: The prediction of roughness for each joint profile using Sa.

\begin{tabular}{|c|c|c|c|c|c|c|c|}
\hline Reference & No. & Profile length $(\mathrm{mm})$ & JRC & $S a$ (FLTR) & $\mathrm{Sa}$ (FRTL) & JRC (FLTR) & JRC (FRTL) \\
\hline \multirow{3}{*}{ Yang [20] } & 1 & 50 & 13.18 & 0.03975 & 0.04331 & 12.839 & 14.313 \\
\hline & 2 & 100 & 13.33 & 0.03975 & 0.04331 & 11.020 & 12.102 \\
\hline & 3 & 200 & 13.46 & 0.03975 & 0.04331 & 9.459 & 10.233 \\
\hline Oding [36] & 4 & 100 & $4-6$ & 0.02988 & 0.02883 & 7.567 & 7.149 \\
\hline \multirow[t]{2}{*}{ Ozvan et al. [37] } & 5 & 100 & 12 & 0.04250 & 0.05944 & 11.863 & 16.275 \\
\hline & 6 & 50 & 19.2 & 0.09925 & 0.07676 & 32.883 & 26.161 \\
\hline \multirow[t]{2}{*}{ Zhang et al. [30] } & 7 & 50 & 17.1 & 0.07485 & 0.04668 & 25.558 & 15.656 \\
\hline & 8 & 50 & 14.6 & 0.04411 & 0.05582 & 14.634 & 19.101 \\
\hline \multirow{9}{*}{ Yong et al. [38] } & 9 & 100 & $14-16$ & 0.04264 & 0.05156 & 11.905 & 14.365 \\
\hline & 10 & 100 & $18-20$ & 0.08107 & 0.05344 & 20.657 & 14.839 \\
\hline & 11 & 100 & $14-16$ & 0.05951 & 0.03672 & 16.291 & 10.041 \\
\hline & 12 & 100 & $10-12$ & 0.03907 & 0.01794 & 10.806 & 1.913 \\
\hline & 13 & 100 & $6-8$ & 0.02931 & 0.01893 & 7.344 & 2.479 \\
\hline & 14 & 100 & $10-12$ & 0.03780 & 0.02028 & 10.396 & 3.217 \\
\hline & 15 & 100 & $4-6$ & 0.02517 & 0.02123 & 5.593 & 3.709 \\
\hline & 16 & 100 & $2-4$ & 0.01879 & 0.01614 & 2.402 & 0.818 \\
\hline & 17 & 100 & $2-4$ & 0.01588 & 0.01975 & 0.650 & 2.928 \\
\hline \multirow{4}{*}{ Ye et al. [39] } & 18 & 170 & 7.704 & 0.02481 & 0.02431 & 5.128 & 4.923 \\
\hline & 19 & 170 & 8.007 & 0.02832 & 0.02422 & 6.448 & 4.887 \\
\hline & 20 & 170 & 7.955 & 0.03318 & 0.02304 & 8.023 & 4.386 \\
\hline & 21 & 170 & 6.331 & 0.03212 & 0.02588 & 7.701 & 5.550 \\
\hline
\end{tabular}

After the uniaxial compression test and direct shear test, the shear strength of joint specimens in different directions was obtained. The value of JCS in JRC-JCS model is the uniaxial compressive strength of mortar, which is $58.10 \mathrm{MPa}$. The values of JCS and basic friction angle in JRC-JCS model were separately obtained from the uniaxial compressive test of mortar and the direct shear test of plane joints. They are $58.10 \mathrm{MPa}$ and $39.79^{\circ}$. Finally, the JRC of joint surface in different directions could be calculated by JRC-JCS model [10], and its value was the average value of the calculation results under four normal stresses:

$$
\mathrm{JRC}=\frac{\tan ^{-1}\left(\tau / \sigma_{n}\right)-\varphi_{r}}{\lg \left(\mathrm{JCS} / \sigma_{n}\right)} .
$$

Table 8 showed the comparison between the JRC results of two joint surfaces predicted by $S a$ and backcalculated by the JRC-JCS model. It could be seen that the JRC prediction results obtained by $\mathrm{Sa}$ were very close to those obtained from the laboratory tests. The minimum absolute error was $5 \%$, and the maximum absolute error was $25.78 \%$. In addition, the roughness of joints J-1 and J-2 had obvious anisotropy. The aforementioned results showed that the new statistical 


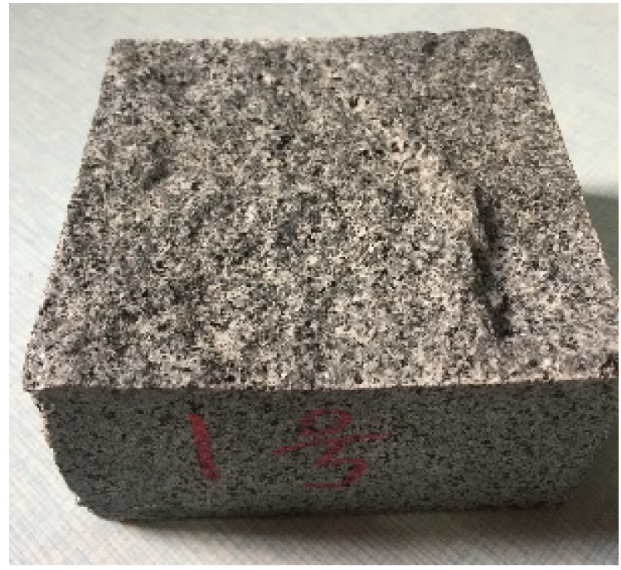

(a)

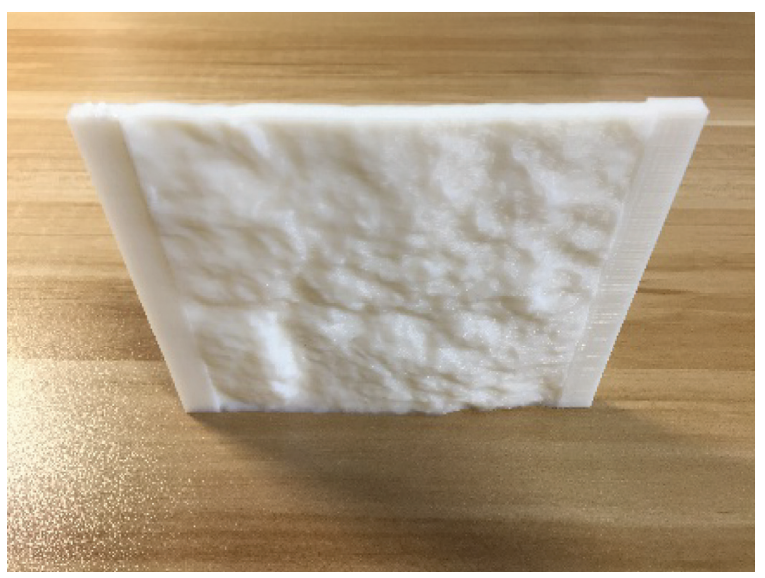

(c)

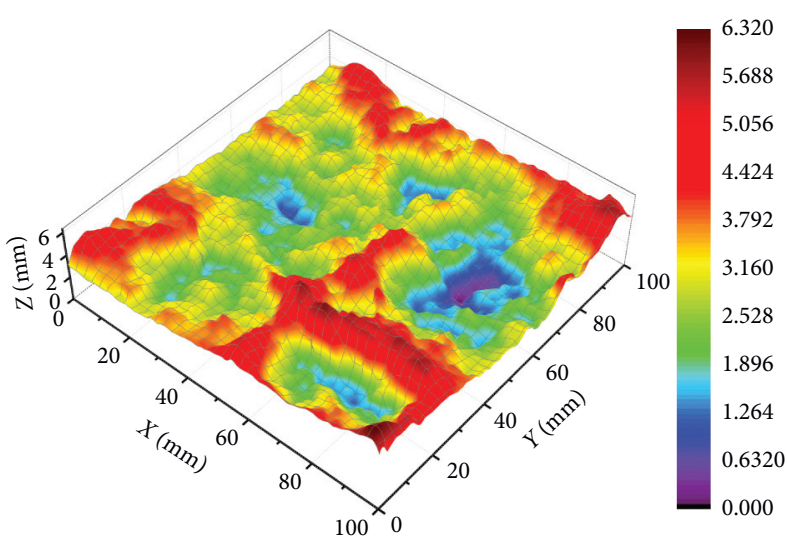

(b)

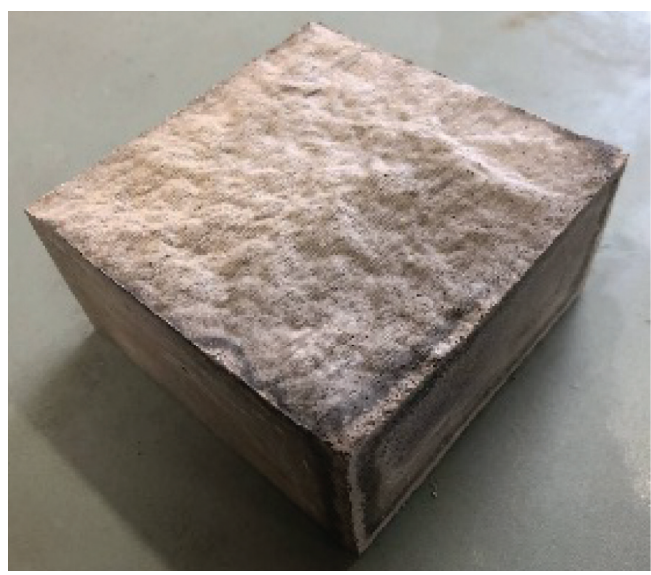

(d)

Figure 13: The two joint specimens used to evaluate roughness. (a) Natural joint sample. (b) Joint surface model. (c) Joint surface mold. (d) Mortar joint specimen.

TABLE 8: Comparison of JRC results predicted by $S a$ and backcalculated by JRC-JCS model.

\begin{tabular}{lcccc}
\hline \multirow{2}{*}{ Joint number } & Shear direction & JRC values & Absolute error (\%) \\
& & JRC-JCS & 10.41 & 12.20 \\
$\mathrm{~J}-1$ & Direction 1 & 11.68 & 10.93 & 14.18 \\
& Direction 2 & 12.48 & 8.26 & 15.62 \\
& Direction 3 & 9.55 & 10.54 & 7.69 \\
\hline $\mathrm{J}-2$ & Direction 4 & 11.35 & 7.71 & 23.09 \\
& Direction 1 & 9.49 & 13.69 & 5.77 \\
& Direction 2 & 14.48 & 11.36 & 5.55 \\
\hline
\end{tabular}

parameter Sa proposed in this paper can well reflect the joint surface roughness considering the shear direction.

\section{Conclusion}

As a parameter to quantitatively evaluate the roughness, JRC is very important for predicting the shear strength of rock joints and evaluating the stability of rock mass. At present, most statistical parameters used for estimating the
JRC values of joint profile ignored the directional differences of rough morphology. Therefore, this paper proposed a new statistical parameter $S a$ for solving this problem.

First, the 10 standard roughness joint profiles proposed by Barton were digitized using data processing software as a research basis. Then, the calculation results of the existing parameters, such as $Z_{2}$ and $R_{P}$, were similar to those of the previous ones, which indicated that the data process can be considered correct. By calculating the existing statistical 
parameters $\left(\theta_{p}^{+}\right.$and $\left.Z_{2}^{\prime}\right)$ considering the shear direction, it was found that the correlation between them and JRC was not very good.

The concept of area difference (DA) was proposed to describe the roughness of the joint surface, and only the case of a positive area difference was considered to reflect the roughness in a certain direction. The results showed that $\mathrm{Sa}$ and $S s$ obtained under the shear condition of FLTR satisfied strong relevance with JRC backcalculated under the shear condition of FLTR. In addition, the correlation between $\mathrm{Sa}$ and $S s$ obtained under the shear condition of FRTL and JRC backcalculated under the shear condition of FLTR was poor. The correlation coefficient between $S a$ and JRC was higher. So, the $S a$ was recommended as a new statistical parameter to predict the JRC of the joint profile.

The reverse JRC of the standard profiles were obtained by substituting $S a$ shear condition obtained under the shear condition of FRTL into (8). The results showed that the JRC of each profile varied greatly in different directions, which indicated that $S a$ can well reflect the directionality of roughness. As the sampling interval increased, the correlation coefficient of the fitting formula between $\mathrm{Sa}$ and JRC decreased rapidly, and the deviations between $\mathrm{JRC}_{\mathrm{pre}}$ and $\mathrm{JRC}_{\text {true }}$ gradually increased. Those indicated that the sampling interval of joint profile should be as small as possible or cannot accurately reflect the roughness morphology.

The roughness of joint profile obtained from the literature was reestimated in this paper. The forward and reverse JRC results showed that the roughness of the joint profile in different directions was independent and varied greatly. What is more, the point cloud data of two natural rock joint surfaces were obtained by $3 \mathrm{D}$ scanning technology, and the corresponding physical tests were carried out based on joint specimens made of mortar. The JRC of joint surface in different directions were predicted using the $S a$, and the result was very close to that of JRC-JCS model. It could be confirmed that the new statistical parameter $S a$ proposed in this paper can well describe the joint roughness considering the shear direction.

\section{Data Availability}

The data used to support the findings of this study are included within the article.

\section{Conflicts of Interest}

The authors declare that they have no conflicts of interest.

\section{Acknowledgments}

This study was funded by the National Natural Science Foundation of China (11902249, 51179153, and 11872301), Natural Science Basic Research Program of Shaanxi (2020JM-453), and Scientific Research Program of Shaanxi Provincial Education Department (17JS091 and 2019JQ395).

\section{References}

[1] E. Hoek, "Strength of jointed rock masses," Géotechnique, vol. 33, no. 33, pp. 187-223, 1983.

[2] D. D. Pollard and P. Segall, "Theoretical displacements and stresses near fractures in rock: with applications to faults, joints, veins, dikes, and solution surfaces," Fracture Mechanics of Rock, vol. 13, no. 8, pp. 277-349, 1987.

[3] X. Yang, P. H. S. W. Kulatilake, H. Jing, and S. Yang, "Numerical simulation of a jointed rock block mechanical behavior adjacent to an underground excavation and comparison with physical model test results," Tunnelling and Underground Space Technology, vol. 50, pp. 129-142, 2015.

[4] M. He, Z. Zhang, J. Zheng, F. Chen, and N. Li, "A new perspective on the constant $\mathrm{mi}$ of the hoek-brown failure criterion and a new model for determining the residual strength of rock," Rock Mechanics and Rock Engineering, vol. 53, no. 9, pp. 3953-3967, 2020.

[5] P. L. Newland and B. H. Allely, "Volume changes in drained taixial tests on granular materials," Géotechnique, vol. 7, no. 1, pp. 17-34, 2015.

[6] F. D. Patton, "Multiple modes of shear failure in rock," in Proceeding of the Congress of International Society of Rock Mechanics, pp. 509-513, Denver, CO, USA, September 1966.

[7] M. Bahaaddini, G. Sharrock, and B. K. Hebblewhite, "Numerical direct shear tests to model the shear behaviour of rock joints," Computers and Geotechnics, vol. 51, no. 51, pp. 101-115, 2013.

[8] M. Abolfazli and A. Fahimifar, "The effects of rock joint characteristics and normal stress level on the stiffness of rock joints," Arabian Journal of Geosciences, vol. 13, no. 19, pp. 1-12, 2020.

[9] N. Barton, "Review of a new shear-strength criterion for rock joints," Engineering Geology, vol. 7, no. 4, pp. 287-332, 1973.

[10] N. Barton and V. Choubey, "The shear strength of rock joints in theory and practice," Rock Mechanics, vol. 10, no. 1-2, pp. 1-54, 1977.

[11] P. Press, "Incorporated, suggested methods for the quantitative description of discontinuities in rock masses," International Journal of Rock Mechanics \& Mining Science \& Geomechanics Abstracts, vol. 15, no. 6, pp. 319-368, 1978.

[12] P. H. S. W. Kulatilake, G. Shou, T. H. Huang, and R. M. Morgan, "New peak shear strength criteria for anisotropic rock joints," International Journal of Rock Mechanics and Mining Sciences \& Geomechanics Abstracts, vol. 32, no. 7, pp. 673-697, 1995.

[13] A. J. Beer, D. Stead, and J. S. Coggan, “Technical note estimation of the joint roughness coefficient (JRC) by visual comparison," Rock Mechanics and Rock Engineering, vol. 35, no. 1, pp. 65-74, 2002.

[14] S. M. Hsiung, A. Ghosh, M. P. Ahola, and A. H. Chowdhury, "Assessment of conventional methodologies for joint roughness coefficient determination," International Journal of Rock Mechanics and Mining Sciences \& Geomechanics Abstracts, vol. 30, no. 7, pp. 825-829, 1993.

[15] N. Barton and S. Bandis, "Effects of block size on the shear behavior of jointed rock," in Proceedings of the 23rd U.S Symposium on Rock Mechanics (USRMS), pp. 739-760, American Rock Mechanics Association, New York City, NY, USA, June 1982.

[16] S. G. Du, Y. Chen, and L. Fan, "Mathematical expression of JRC modified straight edge," Journal of Engineering Geology, vol. 41996, in Chinese. 
[17] N. Turk, M. Greig, W. Dearman, and F. Amin, "Characterization of rock joint surfaces by fractal dimension," in Proceedings of the U.S Symposium on Rock Mechanics (USRMS), New York City, NY, USA, June 1987.

[18] Y.-H. Lee, J. R. Carr, D. J. Barr, and C. J. Haas, “The fractal dimension as a measure of the roughness of rock discontinuity profiles," International Journal of Rock Mechanics and Mining Sciences \& Geomechanics Abstracts, vol. 27, no. 6, pp. 453-464, 1990.

[19] R. Tse and D. M. Cruden, "Estimating joint roughness coefficients," International Journal of Rock Mechanics and Mining Sciences \& Geomechanics Abstracts, vol. 16, no. 5, pp. 303-307, 1979.

[20] Z. Y. Yang, S. C. Lo, and C. C. Di, "Reassessing the joint roughness coefficient (JRC) estimation using Z 2," Rock Mechanics and Rock Engineering, vol. 34, no. 3, pp. 243-251, 2001.

[21] M. Abolfazli and A. Fahimifar, "An investigation on the correlation between the joint roughness coefficient (JRC) and joint roughness parameters," Construction and Building Materials, vol. 259, Article ID 120415, 2020.

[22] X. Yu and B. Vayssade, "Joint profiles and their roughness parameters," International Journal of Rock Mechanics and Mining Sciences \& Geomechanics Abstracts, vol. 28, no. 4, pp. 333-336, 1991.

[23] H.-S. Jang, S.-S. Kang, and B.-A. Jang, "Determination of joint roughness coefficients using roughness parameters," Rock Mechanics and Rock Engineering, vol. 47, no. 6, pp. 2061-2073, 2014.

[24] B. S. A. Tatone and G. Grasselli, "A new 2D discontinuity roughness parameter and its correlation with JRC," International Journal of Rock Mechanics and Mining Sciences, vol. 47, no. 8, pp. 1391-1400, 2010.

[25] B. Zheng and S. Qi, "A new index to describe joint roughness coefficient (JRC) under cyclic shear," Engineering Geology, vol. 212, pp. 72-85, 2016.

[26] M. Huang, C.-c. Xia, P. Sha, C.-r. Ma, and S.-g. Du, "Correlation between the joint roughness coefficient and rock joint statistical parameters at different sampling intervals," $A d$ vances in Civil Engineering, vol. 2019, pp. 1-9, 2019.

[27] W. Fan and P. Cao, "A new 3D JRC calculation method of rock joint based on laboratory-scale morphology testing and its application in shear strength analysis," Bulletin of Engineering Geology and the Environment, vol. 79, no. 1, pp. 345-354, 2020.

[28] N. H. Maerz, J. A. Franklin, and C. P. Bennett, "Joint roughness measurement using shadow profilometry," International Journal of Rock Mechanics and Mining Sciences \& Geomechanics Abstracts, vol. 27, no. 5, pp. 329-343, 1990.

[29] T. Belem, F. Homand-Etienne, and M. Souley, "Quantitative parameters for rock joint surface roughness," Rock Mechanics and Rock Engineering, vol. 33, no. 4, pp. 217-242, 2000.

[30] G. Zhang, M. Karakus, H. Tang, Y. Ge, and L. Zhang, "A new method estimating the 2D Joint Roughness Coefficient for discontinuity surfaces in rock masses," International Journal of Rock Mechanics and Mining Sciences, vol. 72, pp. 191-198, 2014.

[31] C. S. Wang, L. Q. Wang, and Y. F. Ge, “A nonlinear method for determining two-dimensional joint roughness coefficient based on statistical parameters," Rock and Soil Mechanics, vol. 38, no. 2, pp. 565-573, 2017.

[32] F. Homand, T. Belem, and M. Souley, "Friction and degradation of rock joint surfaces under shear loads," International
Journal for Numerical and Analytical Methods in Geomechanics, vol. 25, no. 10, pp. 973-999, 2001.

[33] B. Liu, H. B. Li, and X. Zhu, "Experiment simulation study of strength degradation of rock joints under cyclic shear loading," Chinese Journal of Rock Mechanics \& Engineering, vol. 30, no. 10, pp. 2033-2039, 2011, in Chinese.

[34] B. Li, Y. Jiang, T. Mizokami, K. Ikusada, and Y. Mitani, "Anisotropic shear behavior of closely jointed rock masses," International Journal of Rock Mechanics and Mining Sciences, vol. 71, pp. 258-271, 2014.

[35] J.-Y. Huan, M.-M. He, Z.-Q. Zhang, and N. Li, “A new method to estimate the joint roughness coefficient by back calculation of shear strength," Advances in Civil Engineering, vol. 2019, Article ID 7897529, 15 pages, 2019.

[36] N. E. Odling, "Natural fracture profiles, fractal dimension and joint roughness coefficients," Rock Mechanics and Rock Engineering, vol. 27, no. 3, pp. 135-153, 1994.

[37] A. Özvan, İ. Dinçer, A. Acar, and B. Özvan, "The effects of discontinuity surface roughness on the shear strength of weathered granite joints," Bulletin of Engineering Geology and the Environment, vol. 73, no. 3, pp. 801-813, 2014.

[38] R. Yong, J. Ye, Q. F. Liang, M. Huang, and S. G. Du, "Estimation of the joint roughness coefficient (JRC) of rock joints by vector similarity measures," Bulletin of Engineering Geology \& the Environment, vol. 77, pp. 1-15, 2017.

[39] J. Ye, R. Yong, Q.-F. Liang, M. Huang, and S.-G. Du, "Neutrosophic functions of the joint roughness coefficient and the shear strength: a case study from the pyroclastic rock mass in shaoxing city, China," Mathematical Problems in Engineering, vol. 2016, Article ID 4825709, 9 pages, 2016.

[40] N. Barton, S. Bandis, and K. Bakhtar, "Strength, deformation and conductivity coupling of rock joints," International Journal of Rock Mechanics and Mining Sciences \& Geomechanics Abstracts, vol. 22, no. 3, pp. 121-140, 1985. 